AperTO - Archivio Istituzionale Open Access dell'Università di Torino

\title{
Water-Soluble Nitric-Oxide-Releasing Acetylsalicylic Acid \\ (ASA) Prodrugs
}

\section{This is the author's manuscript}

Original Citation:

Availability:

This version is available http://hdl.handle.net/2318/140328

since 2016-07-18T08:05:51Z

Published version:

DOI:10.1002/cmdc.201300105

Terms of use:

Open Access

Anyone can freely access the full text of works made available as "Open Access". Works made available under a Creative Commons license can be used according to the terms and conditions of said license. Use of all other works requires consent of the right holder (author or publisher) if not exempted from copyright protection by the applicable law. 


\section{(3) \\ UNIVERSITÀ DEGLI STUDI DI TORINO}

This is the accepted version of the following article:

Water-soluble nitric-oxide-releasing aspirin pro-drugs

ChemMedChem 2013, 8, 1199 - 1209.

Supporting information for this article is available on the WWW under http://dx.doi.org/10.1002/cmdc.201300105.

which has been published in final form at 


\title{
Water-soluble nitric-oxide-releasing aspirin pro-drugs
}

\author{
Barbara Rolando, ${ }^{1}$ Loretta Lazzarato,${ }^{1}$ Monica Donnola,${ }^{1}$ Elisabetta Marini, ${ }^{1}$ Sony Joseph,${ }^{1}$ \\ Giuseppina Morini, ${ }^{2}$ Cristina Pozzoli, ${ }^{2}$ Roberta Fruttero, ${ }^{1, *}$ Alberto Gasco ${ }^{1}$
}

Dipartimento di Scienza e Tecnologia del Farmaco, Università degli Studi di Torino, Via Pietro Giuria 9, 10125 Torino, Italy, Dipartimento di Neuroscienze, Università degli Studi di Parma, Via Volturno 39, 40100 Parma, Italy

${ }^{1}$ University of Torino.

${ }^{2}$ University of Parma.

E-mail address: roberta.fruttero@unito.it

\section{Summary}

A new series of water-soluble (R-benzoyloxy) methyl esters of aspirin bearing at the benzoyl ring both alkyl chains containing nitric oxide (NO)-releasing nitrooxy groups and solubilizing moieties, was synthesized, and the products evaluated as true aspirin pro-drugs. Most products are solid substances and all posses good water solubility. They are quite stable in acid solutions $(\mathrm{pH}=1)$ and less stable at physiological pH. In human serum they are immediately metabolized by esterases, producing a mixture of aspirin (ASA), salicylic acid (SA), and of the related NO-donor benzoic acids, with other minor products. Due to aspirin release, the pro-drugs are capable of inhibiting collagen-induced platelet aggregation of human platelet-rich plasma. The simple NO-donor benzoic acids 28 and 48, studied as representative models of the whole class of benzoic acids formed following metabolism of the prodrugs in serum, did not trigger antiaggregatory activity when tested at $300 \mu \mathrm{M}$ concentration. Only $\mathbf{2 8}$ displays quite potent NO-dependent vasodilatatory action. For two selected pro-drugs, $\mathbf{3 8}$ and 49, in vivo gastrotoxicity and anti-inflammatory properties are also reported: their anti-inflammatory activities are similar to that of aspirin when tested in the carrageenan-induced paw edema assay in rats. The gastrotoxicity the two pro-drugs was lower than that of aspirin in a lesion model in rats.

\section{Introduction}

Nitric oxide (NO)-donor aspirins (NO-ASA) are a class of products that has received particular attention in recent years. ${ }^{1,2}$ The pharmacological rationale for developing them was that NO displays gastrosparing properties and consequently could be expected to reduce the well-known gastrotoxicity of ASA, without reducing its antithrombotic and anti-inflammatory properties. ${ }^{3-5}$ NOASAs have the general structure $\mathbf{1}$ (Chart 1) in which the carboxylic group of acetylsalicylic acid 
(ASA) is linked through an enzymatically-labile ester bridge to a substructure containing a NOdonor moiety, belonging to the nitrate, furoxan, NONOate class. Examples of such hybrids are reported in the literature. ${ }^{6-8}$ The action of these substances is complex, and there is no clear evidence to date that they are true pro-drugs of ASA, namely that they are capable of releasing ASA in the plasma or other tissues. The absence of a negative charge, which conversely is present on ASA at physiological $\mathrm{pH}\left(\mathrm{ASA}, \mathrm{pK}_{\mathrm{a}}=3.5\right)$, renders their acetyloxy group highly susceptible to enzymatic cleavage. ${ }^{9}$ These products should thus be considered pro-drugs of salicylic acid (SA) rather than of ASA. We recentl showed that (nitrooxyacyloxy)methyl esters of ASA and related carbonates are true ASA pro-drugs (2, 3 Chart 1). ${ }^{10,11}$ In these structures the deacetylation rate constant is lower than the hydrolytic rate constant of the carbonyloxymethyloxycarbonyl moiety, and consequently the products are able to release ASA in amounts that depend on the structure of the NO donor acyl moiety. One problem with these double esters is their poor water solubility; many are oily in nature. This study describes a new series of (nitrooxyacyloxy)methyl esters of ASA, which are true ASA pro-drugs and that posses good water solubility and a solid physical state. In these products, the NO-donor nitrooxyacyloxy moiety comprises the benzoyloxy scaffold, bearing a nitrooxyalkyloxy chain at the para position, and a solubilizing substructure at the meta position (Chart 2). In most of the derivatives (38-44) the solubilizing substructure is a metabolically-labile aminoacyloxy group (I, Chart 2); in the case of compound 49 (Chart 2), the morpholinomethyl solubilizing substructure is directly jointed to the aromatic ring. The synthesis, solubility, stability in different media, release of ASA, together with in vitro platelet antiaggregatory profile of all these new pro-drugs are discussed. The in vivo gastrotoxicity and antiinflammatory properties are also reported for two selected compounds, $\mathbf{3 8}$ and $\mathbf{4 9 .}$

Chemicals. The products bearing aminoacyloxy groups were obtained as reported in Schemes 1 - 3 . The commercially-available 3,4-dihydroxybenzaldehyde (4) was bromoalkylated with 1,3dibromopropane in acetonitrile solution to give $\mathbf{5}$ that, in turn, was transformed by action of $\mathrm{AgNO}_{3}$ into the related nitrooxy analogue 7. This intermediate was reacted under inert atmosphere with the appropriate tert-butoxycarbonyl (BOC) protected amino acid in $\mathrm{CH}_{2} \mathrm{Cl}_{2}$ solution, in the presence of 1-ethyl-3-(3-dimethylaminopropyl)carbodiimide hydrochloride $\quad(\mathrm{EDC} \cdot \mathrm{HCl}) \quad$ and 4(dimethylamino)pyridine (DMAP), to afford the related aminoacyloxy substituted aldehydes 9, 1114. The corresponding acids $15,17-20$ were obtained by oxidation with $\mathrm{KMnO}_{4}$ in acetone solution. The acid 16 and its intermediates 10, 8 were obtained in the same manner as its inferior homologue 15, the only difference being that the starting material was the chloro substituted compound $\mathbf{6}$. Coupling of these acid derivatives 15-20 with ASA chloromethyl ester 29, in the presence of $\mathrm{Cs}_{2} \mathrm{CO}_{3}$, gave the oxymethyloxy esters 30-35, and subsequent removal of BOC-protection in 
dioxane containing $\mathrm{HCl}$ yielded the desired compounds 38-43. The final para-nitroxybutyloxy product 39 and the its intermediates $16,10,8$, were obtained in the same manner as its inferior homologue 38 and related intermediates. For the preparation of the dinitrooxy substituted pro-drug 44 3,4-dihydroxybenzaldehyde (4) was alkylated with allylbromide to give the unsaturated aldehyde 21. This latter was treated with (BOC)-protected $\beta$-alanine to give 22, following the general conditions described above for the preparation of the (BOC)-protected aminoacyloxy substituted aldehydes. This intermediate was transformed by action of iodine and $\mathrm{AgNO}_{3}$ into the dinitrooxyester $\mathbf{2 3}$, which, in turn was oxidized with $\mathrm{KMnO}_{4}$ to the corresponding acid $\mathbf{2 4}$. The final compound 44 was obtained from 24 through the intermediate 36, using the procedures described above to prepare the aminoacyloxy substituted pro-drugs from the related acids.

Scheme 2 reports the synthesis of the simple NO-donor benzoic acids 28. In particular, the ester derivative 27 was obtained starting from the methyl ester of 3,4-dihydroxybenzoic acid $\mathbf{2 5}$, in the same manner as its aldehyde analogue 7. 27 was then hydrolyzed to the corresponding carboxylic acid 28 with $\mathrm{NaOH}$ in a $\mathrm{THF} / \mathrm{H}_{2} \mathrm{O}$ mixture heated to $40{ }^{\circ} \mathrm{C}$.

Scheme 4 reports the synthetic pathway followed to obtain the target product 49 containing the morpholino moiety as solubilizing group. The ester 45 treated with 1,3-dibromopropane in acetonitrile solution gave rise to the bromocompound 46. This product, by action of $\mathrm{AgNO}_{3}$ in acetonitrile solution, was transformed into the nitrooxy analogue $\mathbf{4 7}$, in turn hydrolyzed to the related acid $\mathbf{4 8}$, which was coupled with $\mathbf{2 9}$ to give the desired final structure.

All the basic products were successfully transformed into the related hydrochlorides, with the sole exception of the morpholino derivative 49, which was characterized as an oxalate. Most of these salts are solid compounds having well-defined melting points (Table 1). Products 39 and 41, which are both superior homologues of $\mathbf{3 8}$, the former at the aminoacyloxy chain, the latter at the nitrooxyalkyloxy moiety, are oily. Compound 44, formally derived from 38 by introducing a second nitrooxy group $\alpha$-positioned to the first, is a foam.

Water solubility. The water solubility values of all compounds described here are given in Table 1 . All products display good water solubility, in most cases higher than that of ASA ( $3 \mathrm{~g} / \mathrm{l}$, The Merck Index Fourteenth Edition). For the solid hydrochlorides, the higher the solubility, the lower the melting point.

Hydrolysis studies. Most of the pro-drugs described here (compounds 38-44) contain three substructures susceptible to hydrolysis: the acetyloxy group, the aminoacyloxy group, and the carbonyloxymethyloxycarbonyl moiety. The possible routes whereby these products can hydrolyze 
are reported in Scheme 5. Hydrolysis was assessed by high performance liquid chromatography (HPLC) in $\mathrm{pH} 1$ and $\mathrm{pH} 7.4$ buffered solutions, as well as in human serum. In human serum, hydrolysis is catalyzed by carboxylesterases, ubiquitous enzymes that display broad substrate specificity: the same ester can often be hydrolyzed by more than one enzyme. ${ }^{12}$ In human serum, the fate of all compounds was very similar: the observed half-lives were $<1$ min (see Table 1). The metabolites were monitored for $6 \mathrm{~h}$. After 10 minutes, only ASA, SA, IV, and traces of II and III were present: this means that the aminoacyloxy and the carbonyloxymethyloxycarbonyl moieties hydrolyze simultaneously, and much more faster than the related acetyloxy functions. After $6 \mathrm{~h}$, only SA and IV, accompanied by traces of ASA, were present. Figure 1 shows the concentration over time of the metabolites of compound 38, as an example of the performance of the class as a whole. This is an interesting result, and shows that these products are true ASA pro-drugs. Maximal ASA production is reached for all compounds after 2-5 min. These values, expressed as $\%$ of the initial concentration of the compounds, are reported in Table 1. They are similar for all products, and fall in the range 50-57\%. Table 1 also gives the areas under the ASA release curves, measured after ten minutes' incubation $\left(\mathrm{AUC}_{0-10 \mathrm{~min}}\right)$. They do not entirely parallel the corresponding max ASA \% values, which suggests that the substitution pattern at the benzoyl ring exerts some influence on the hydrolysis of the carbonyloxymethyloxycarbonyl moieties.

The products are more stable in physiological solution $(\mathrm{pH}=7.4$ phosphate buffer $)$ than in serum: after 3 hours' incubation, the sole metabolite formed was III. The hydrolysis strictly followed firstorder kinetic, and the observed pseudo-first-order constants $\left(k_{\mathrm{obs}}\right)$ were calculated from the slopes of linear plots of the logarithm of the remaining ester against time: the corresponding half-lives (Table) were obtained from the eq 1.

$$
t_{1 / 2}=0.693 / k_{\text {obs }}(1)
$$

The most stable pro-drugs are compounds 39 (86 $\mathrm{min}), 38$ (57 $\mathrm{min}$ ), and 44 (20 min), bearing the $\beta$ aminopropionyloxy chain at the 3-position of the benzoyl ring. The other compounds show $t_{1 / 2}$ values in the range 10-15 $\mathrm{min}$.

In $\mathrm{pH}=1$ buffered solution, all products remained $70-90 \%$ unchanged after $3 \mathrm{~h}$ (Table 1); during this time, only III had formed.

Unlike the products discussed above, the pro-drug 49 bears the water-solubilizing morpholinomethyl group directly linked to the benzoyl scaffold, rather than through a vulnerable ester bridge. Consequently, only the acetyloxy and the carbonyloxymethyloxycarbonyl moieties undergo hydrolysis, with a consequent decrease in the number of possible metabolites (see Scheme 5). This product is more stable in serum than the pro-drugs discussed previously, due to the lack of the very vulnerable aminoacyloxy function. Like the other pro-drugs, its deacetylation rate constant 
is lower than the hydrolytic rate constant of the carbonyloxymethyloxycarbonyl moiety, which enables ASA to be present among the metabolites. The hydrolysis strictly follows a first order kinetics. Its half-life, calculated from the observed pseudo-first-order rate constant, is $2.2 \mathrm{~min}$. Figure 2 shows the concentrations of the metabolites over time for this product. The maximum concentration of aspirin is reached after $6 \mathrm{~min}$, and the amount of aspirin released (\% max and AUC values) is lower than the values measured for all other pro-drugs (see Table 1). After $6 \mathrm{~h}$, only 48, $\mathrm{SA}$, and traces of ASA were present. The compound is very stable, not only in $\mathrm{pH}=1$ buffered solution, but also at physiological $\mathrm{pH}$.

\section{Pharmacological studies.}

Platelet Antiaggregatory Activity. Antiaggregatory activity of the new NO-aspirins was assessed through collagen-induced platelet aggregation of human platelet rich plasma (PRP), taking ASA as reference standard. The inhibitory effect of a compound was tested by adding it to PRP $10 \mathrm{~min}$ before addition of the stimulus. All products displayed a concentration-dependent inhibitory effect. Their antiaggregatory potencies, expressed as $\mathrm{IC}_{50}$, are in Table 1. As previously mentioned, compounds IV and $\mathbf{4 8}$ are the metabolites formed rapidly from the pro-drugs under study, under the action of serum esterases. The antiaggregatory action of $\mathbf{2 8}$ and $\mathbf{4 8}$, chosen as prototypes of these acid metabolites, was likewise evaluated. No antiaggregatory activity was observed when the products were tested at $300 \mu \mathrm{M}$ concentration, meaning that NO does not play a significant role in the antiaggregatory effect of these pro-drugs, and that this activity is largely due to their capacity to produce ASA. The relationship between $\mathrm{AUC}_{0-10 \min }$ and $\mathrm{IC}_{50}$ values for the entire series of prodrugs studied is depicted in Figure 3.

Vasodilator activity. All the pro-drugs can be expected to display vasodilator properties in vivo, due to the rapid formation of the relative NO-donor benzoic acid metabolites (IV and $\mathbf{4 8}$ ) under the action of plasma esterases. The vasodilator activity of two selected acids, 28 and $\mathbf{4 8}$, chosen as prototypes of these metabolites, was evaluated on endothelium-denuded rat-aorta strips, precontracted with phenylephrine. The first compound (28), which contains the metahydroxybenzoic acid moiety that is common to all the aminoacyloxy-substituted pro-drugs, was found to relax the contracted tissue in a concentration-dependent manner. Its potency, expressed as $\mathrm{EC}_{50}$, is in Table 1 . When the experiments were repeated in the presence of $1 \mu \mathrm{ODQ}(1 \mathrm{H}-$ [1,2,4] oxadiazolo[4,3-a]quinoxalin-1-one), a known inhibitor of soluble guanylate cyclase (sGC), the potency decreased (Table 1), in keeping with NO-induced activation of sGC being the mechanism underlying the vasodilator effect. Conversely, the second compound (48) was inactive as a vasodilator, after testing it at up to $100 \mu \mathrm{M}$ concentration. This product contains the same para- 
nitrooxy alkyl chain as $\mathbf{2 8}$, but the water solubilizing group is covalently attached to the benzoic acid scaffold. The lipophilic-hydrofilic balance of the two products differs $\left(\mathbf{2 8}, \log \mathrm{D}^{7.4}=-0.80 ; \mathbf{4 8}\right.$, $\left.\log \mathrm{D}^{7.4}=-1.30\right)$ as do their steric and electronic properties. The former at physiological $\mathrm{pH}$ exists principally as an anionic species (anion form $>99 \%$; $\mathrm{pK}_{\mathrm{a}} \mathrm{COOH}=4.41$ ) while the latter exists as a mixture of anion and zwitterion species (anion form $=54 \%$, zwitterion form $=46 \% ; \mathrm{pK}_{\mathrm{a}}$ соОН $=$ $3.90, \mathrm{pK}_{\mathrm{a} \text { MORPHOLINE }}=7.33$ ). These diverse physico-chemical profiles should give the two products different capacities both to reach and to interact with the target enzyme involved in NO production, thus affording different vasodilator behaviour. This does not rule out that $\mathbf{4 8}$ could release NO in a more complex biological environment: experiments incubating this compound in liver homogenate pointed to a time-dependent production of nitrite and nitrate $\left(\mathrm{NO}_{\mathrm{x}}\right)$, the oxidised metabolites of $\mathrm{NO}$ derived from biotransformation of organic nitrates (data not shown).

Anti-inflammatory activity. The two NO-donor ASA pro-drugs, 38 and 49, and ASA itself, as reference drug, were tested for their anti-inflammatory activity by the carrageenan-induced paw edema test in conscious rats (six per group). The intraplantar injection of carrageenan produced an immediate increase in the paw volume, the inflammatory response peaking 4-5 $\mathrm{h}$ hours after carrageenan injection. The intragastric administration of $120 \mathrm{mg} / \mathrm{kg}$ ASA, just prior to carrageenan injection, led to a significant reduction in edema $(57.4 \pm 6.8 \%, \mathrm{P}<0.01$ versus vehicle-treated controls) assessed $3 \mathrm{~h}$ after ASA administration. Both pro-drugs, 38 and 49, administered at doses equimolar to $120 \mathrm{mgkg}^{-1} \mathrm{ASA}$, caused a significant reduction in paw edema (54.9 $\pm 6.6 \%$ and 51.5 $\pm 4.3 \%$ respectively, $\mathrm{P}>0.01$ versus vehicle-treated controls). The degree of reduction achieved following the administration of the two pro-drugs was comparable to that caused by ASA (Figure 4A).

Acute Gastric Mucosal Damage. The two NO-donor ASA pro-drugs, 38 and 49, and ASA itself, as reference drug, were administered intragastrically to conscious rats (six per group) and after $3 \mathrm{~h}$ the lesion index of each rat stomach was assessed. ASA, at a dose of $120 \mathrm{mg} / \mathrm{kg}$, resulted in the development of macroscopically-detectable lesions located in the gastric mucosa, and characterized by necrosis and hemorrhage, the lesion index being $55.3 \pm 10.4$. In contrast, neither pro-drug, in a dose equimolar to $120 \mathrm{mgkg}^{-1} \mathrm{ASA}$, exerted macroscopically-detectable damaging effects on the gastric mucosa (Figure 4B).

\section{Conclusions}

We have developed a new class of (benzoyloxy)methyl esters of ASA, bearing, at the benzoyl ring, both alkyl chains containing NO-releasing nitrooxy groups and aminoacyloxy solubilizing moieties. 
The products were characterized as salts, and most of them are solid compounds with well-defined melting points. The entire class display good water solubility and acid stability. The products are rapidly metabolized in physiological conditions. In human serum, under the action of esterases, the aminoacyloxy and the carbonyloxymethyloxycarbonyl moieties simultaneously hydrolyze, much more rapidly than do the related acetyloxy functions. The resulting mixture of metabolites includes significant amounts of ASA, and consequently these compounds may be considered true NO-donor ASA-prodrugs. All the products display good antiaggregatory properties as tested on collageninduced platelet aggregation of human platelet-rich plasma; this activity is roughly related to the amount of ASA released in the first ten minutes' incubation. The benzoic acid derivative 28, containing the meta-hydroxybenzoic acid moiety and studied as prototype of the acid metabolites deriving from the aminoacyloxy substituted pro-drugs, is endowed with NO-dependent vasodilator activity, unlike $\mathbf{4 8}$, in which the solubilizing group remains covalently attached to the benzoic acid scaffold. The related pro-drugs 38, 49 display in vivo anti-inflammatory properties and reduced gastrotoxicity as tested on rats.

As a whole, based on their pharmacological and physico-chemical profiles, the pro-drugs described here represent an improved class of NO-donor ASA pro-drugs in comparison to the related less soluble pro-drugs previously described. ${ }^{10}$ For this reason they could be more suitable for clinical applications.

\section{Experimental.}

\section{Chemistry.}

${ }^{1} \mathrm{H}$ and ${ }^{13} \mathrm{C}$ NMR spectra were recorded on a Bruker Avance 300 at 300 and at $75 \mathrm{MHz}$, respectively, using $\mathrm{SiMe}_{4}$ as internal standard. The following abbreviations are used to indicate peak multiplicity: $\mathrm{s}=$ singlet, $\mathrm{d}=$ doublet, $\mathrm{t}=$ triplet, $\mathrm{m}=$ multiplet, $\mathrm{br} \mathrm{s}=$ broad signal. Low resolution mass spectra were recorded with a Finnigan-Mat TSQ-700. Melting points were determined with a capillary apparatus (Buchi 540). Flash column chromatography was performed on silica gel (Merck Kieselgel 60, 230-400 mesh ASTM); PE stands for 40-60 petroleum ether. The progress of the reactions was monitored by thin layer chromatography (TLC) on $5 \mathrm{~cm} \times 20 \mathrm{~cm}$ plates, with layer thickness $0.25 \mathrm{~mm}$. Anhydrous sodium sulfate was used as the drying agent for the organic phases. Organic solvents were removed under vacuum at $30{ }^{\circ} \mathrm{C}$. Elemental analyses $(\mathrm{C}, \mathrm{H}$, N) were performed by REDOX (Monza), and the results are within $0.4 \%$ of the theoretical values. Compounds $\mathbf{2 9} 9^{13}, \mathbf{4 5}^{14}$ were synthesized as indicated in the literature. 


\section{4-(3-Bromopropoxy)-3-hydroxybenzaldehyde (5)}

A solution of 4 (5.00 g, $36.22 \mathrm{mmol}), 1,3$-dibromopropane $(7.35 \mathrm{~mL}, 72.44 \mathrm{mmol})$ and $\mathrm{KHCO}_{3}$ (4.35 g, $43.46 \mathrm{mmol})$ in $\mathrm{CH}_{3} \mathrm{CN}(100 \mathrm{~mL})$ was refluxed for 4 hours. The mixture was then poured into $\mathrm{H}_{2} \mathrm{O}(50 \mathrm{~mL})$ and extracted with EtOAc $(50 \mathrm{~mL})$; the organic layer was washed twice with a saturated solution of $\mathrm{NaHCO}_{3}(50 \mathrm{~mL})$ and extracted twice with $2 \mathrm{~N} \mathrm{NaOH}(50 \mathrm{~mL})$. The last acqueous layers were acidified with $6 \mathrm{M} \mathrm{HCl}$ and then extracted with EtOAc $(3 \times 50 \mathrm{~mL})$. The combined organic layers were dried with $\mathrm{MgSO}_{4}$, filtered, and concentrated under reduced pressure to give the title compound as a pale yellow semisolid; yield: $47 \%$. ${ }^{1} \mathrm{H}-\mathrm{NMR}\left(\mathrm{CDCl}_{3}\right) \delta 2.43$ (qi, $\left.2 \mathrm{H},-\mathrm{OCH}_{2} \mathrm{CH}_{2}-\right), 3.60\left(\mathrm{t}, 2 \mathrm{H},-\mathrm{CH}_{2} \mathrm{Br}\right), 4.32\left(\mathrm{t}, 2 \mathrm{H},-\mathrm{OCH}_{2}-\right), 5.88(\mathrm{~s}, 1 \mathrm{H}, \mathrm{OH}), 7.01\left(\mathrm{~d}, 1 \mathrm{H}, \mathrm{C}_{6} \mathrm{H}_{3}\right)$, $7.42\left(\mathrm{~m}, 1 \mathrm{H}, \mathrm{C}_{6} \mathrm{H}_{3}\right), 7.44-7.46\left(\mathrm{~m}, 1 \mathrm{H}, \mathrm{C}_{6} \mathrm{H}_{3}\right), 9.85$ (s, $\left.1 \mathrm{H},-\mathrm{CHO}\right) .{ }^{13} \mathrm{C}-\mathrm{NMR}\left(\mathrm{CDCl}_{3}\right) \delta 29.3,31.8$, 66.9, 111.2, 114.4, 124.6, 130.8, 146.2, 150.9, 191.1. MS (CI) $m / z$ 259/261 (M+1) ${ }^{+}$

\section{4-(4-Chlorobutoxy)-3-hydroxybenzaldehyde (6)}

A solution of 4 (1.00 g, $7.24 \mathrm{mmol})$, 1-bromo-4-chlorobutane $(2.50 \mathrm{~mL}, 21.7 \mathrm{mmol})$ and $\mathrm{KHCO}_{3}$ (870 mg, $8.69 \mathrm{mmol})$ in $\mathrm{CH}_{3} \mathrm{CN}(20 \mathrm{~mL})$ was refluxed for 14 hours. The mixture was then poured into $\mathrm{H}_{2} \mathrm{O}(30 \mathrm{~mL})$ and extracted with EtOAc $(30 \mathrm{~mL})$; the organic layer was washed twice with a saturated solution of $\mathrm{NaHCO}_{3}(30 \mathrm{~mL})$ and extracted with $2 \mathrm{~N} \mathrm{NaOH}(3 \times 30 \mathrm{~mL})$. The last acqueous layers were acidified with $6 \mathrm{M} \mathrm{HCl}$ and then extracted with EtOAc $(3 \times 30 \mathrm{~mL})$. The combined organic layers were dried with $\mathrm{MgSO}_{4}$, filtered, and concentrated under reduced pressure to give the title compound as a white solid; yield: $60 \%$. m.p. $58-59{ }^{\circ} \mathrm{C}$ (PE/Toluene $\left.1 / 1 \mathrm{v} / \mathrm{v}\right) .{ }^{1} \mathrm{H}-$ NMR $\left(\mathrm{CDCl}_{3}\right) \delta$ 1.95-2.12 (m, 4H, $\left.-\mathrm{OCH}_{2} \mathrm{CH}_{2}-\right), 3.65\left(\mathrm{t}, 2 \mathrm{H},-\mathrm{CH}_{2} \mathrm{Cl}\right), 4.20\left(\mathrm{t}, 2 \mathrm{H},-\mathrm{OCH}_{2} \mathrm{CH}_{2^{-}}\right)$, $5.93(\mathrm{~s}, 1 \mathrm{H}, \mathrm{OH}), 6.97\left(\mathrm{~d}, 1 \mathrm{H}, \mathrm{C}_{6} \mathrm{H}_{3}\right), 7.41-7.46\left(\mathrm{~m}, 2 \mathrm{H}, \mathrm{C}_{6} \mathrm{H}_{3}\right), 9.84$ (s, 1H, -CHO). ${ }^{13} \mathrm{C}-\mathrm{NMR}$ $\left(\mathrm{CDCl}_{3}\right) \delta 26.9,29.6,45.0,68.9,111.4,114.8,125.0,131.2,146.7,151.6,191.6 . \mathrm{MS}(\mathrm{CI}) \mathrm{m} / \mathrm{z}$ $229 / 231(\mathrm{M}+1)^{+}$.

\section{4-(Allyloxy)-3-hydroxybenzaldehyde (21)}

A solution of $4(2.00 \mathrm{~g}, 14.48 \mathrm{mmol})$, allyl bromide $(1.20 \mathrm{~mL}, 14.48 \mathrm{mmol})$ and $\mathrm{KHCO}_{3}(1.74 \mathrm{~g}$, $17.37 \mathrm{mmol})$ in $\mathrm{CH}_{3} \mathrm{CN}(20 \mathrm{~mL})$ was refluxed for 4 hours. The mixture was then poured into $\mathrm{H}_{2} \mathrm{O}$ $(50 \mathrm{~mL})$ and extracted with EtOAc $(50 \mathrm{~mL})$; the organic layer was washed twice with a saturated solution of $\mathrm{NaHCO}_{3}(50 \mathrm{~mL})$ and extracted twice with $2 \mathrm{~N} \mathrm{NaOH}(50 \mathrm{~mL})$. The last acqueous layers were acidified with $6 \mathrm{M} \mathrm{HCl}$ and then extracted with EtOAc $(3 \times 50 \mathrm{~mL})$. The combined organic layers were dried with $\mathrm{MgSO}_{4}$, filtered, and concentrated under reduced pressure to give the title compound as a pale yellow semisolid; yield: $40 \%$. m.p. 57-60 ${ }^{\circ} \mathrm{C}\left(i \operatorname{Pr}_{2} \mathrm{O}\right) .{ }^{1} \mathrm{H}-\mathrm{NMR}\left(\mathrm{CDCl}_{3}\right) \delta 4.69$ (d, 2H, - $\mathrm{OCH}_{2}-$ ) , 5.34-5.46 (m, AMX-like system, 2H, - $\mathrm{CH}=\mathrm{CH}_{2}$ ), 5.99-6.13 (m, AMX-like system, $\left.2 \mathrm{H},-\mathrm{CH}=\mathrm{CH}_{2}+-\mathrm{OH}\right), 6.96\left(\mathrm{~d}, 2 \mathrm{H}, \mathrm{C}_{6} \mathrm{H}_{3}\right), 7.38-7.46\left(\mathrm{~m}, 2 \mathrm{H}, \mathrm{C}_{6} \mathrm{H}_{3}\right), 9.83(\mathrm{~s}, 1 \mathrm{H},-\mathrm{CHO}) .{ }^{13} \mathrm{C}-\mathrm{NMR}$ 
$\left(\mathrm{CDCl}_{3}\right) \delta 69.9,111.5,114.4,119.2,124.4,130.6,131.8,146.3,150.9,191.2 . \mathrm{MS}(\mathrm{CI}) \mathrm{m} / z 179$ $(\mathrm{M}+1)^{+}$.

\section{Methyl 4-(3-bromopropoxy)-3-hydroxybenzoate (31)}

A solution of methyl 3,4-dihydroxybenzoate $(2.10 \mathrm{~g}, 12.5 \mathrm{mmol}), 1,3$-dibromopropane (3.80 $\mathrm{mL}$, $37.5 \mathrm{mmol})$ and $\mathrm{KHCO}_{3}(1.50 \mathrm{~g}, 14.53 \mathrm{mmol})$ in $\mathrm{CH}_{3} \mathrm{CN}(20 \mathrm{~mL})$ was refluxed for 5 hours. The mixture was then poured into $\mathrm{H}_{2} \mathrm{O}(50 \mathrm{~mL})$ and extracted twice with EtOAc $(30 \mathrm{~mL})$; the combined organic layers were washed with brine $(10 \mathrm{~mL})$, dried with $\mathrm{MgSO}_{4}$, filtered, and concentrated under reduced pressure. The crude product was purified by flash chromatography (PE/EtOAc 9/1 v/v to $\mathrm{PE} / \mathrm{EtOAc} 7 / 3 \mathrm{v} / \mathrm{v}$ ) to give the title compound as a white solid; yield: $25 \%$. m.p. 106.5-107.5 ${ }^{\circ} \mathrm{C}$ $\left(i \mathrm{Pr}_{2} \mathrm{O}\right) .{ }^{1} \mathrm{H}-\mathrm{NMR}\left(\mathrm{CDCl}_{3}\right) \delta 2.39$ (qi, 2H, $\left.-\mathrm{OCH}_{2} \mathrm{CH}_{2}-\right), 3.58$ (t, $2 \mathrm{H},-\mathrm{CH}_{2} \mathrm{Br}$ ), $3.88\left(\mathrm{~s}, 3 \mathrm{H},-\mathrm{OCH}_{3}\right)$, $4.26\left(\mathrm{t}, 2 \mathrm{H},-\mathrm{OCH}_{2} \mathrm{CH}_{2-}\right), 5.75(\mathrm{sbr}, 1 \mathrm{H}, \mathrm{OH}), 6.90\left(\mathrm{~d}, 1 \mathrm{H}, \mathrm{C}_{6} \mathrm{H}_{3}\right), 7.57-7.61\left(\mathrm{~m}, 2 \mathrm{H}, \mathrm{C}_{6} \mathrm{H}_{3}\right) .{ }^{13} \mathrm{C}-$ $\mathrm{NMR}\left(\mathrm{CDCl}_{3}\right) \delta 29.4,31.8,50.0,66.7,110.8,115.9,122.8,132.1,145.3,149.4,166.8 . \mathrm{MS}(\mathrm{CI}) \mathrm{m} / \mathrm{z}$ $289 / 291(\mathrm{M}+1)^{+}$.

\section{Methyl 4-(3-bromopropoxy)-3-(morpholin-4-ylmethyl)benzoate (46)}

To a solution of $27(2.00 \mathrm{~g}, 7.90 \mathrm{mmol})$ in $\mathrm{CH}_{3} \mathrm{CN}(12 \mathrm{~mL}) \mathrm{K}_{2} \mathrm{CO}_{3}(1.66 \mathrm{~g}, 12.0 \mathrm{mmol})$ and 1,3dibromopropane $(3.96 \mathrm{~mL}, 39.0 \mathrm{mmol})$ were added and the mixture was heated under reflux for $6 \mathrm{~h}$. The cooled reaction mixture was then poured into $\mathrm{H}_{2} \mathrm{O}(50 \mathrm{~mL})$ and extracted with EtOAc $(3 \times 50$ $\mathrm{mL})$ The combined organic layers were washed with $\mathrm{H}_{2} \mathrm{O}(25 \mathrm{~mL})$, brine $(25 \mathrm{~mL})$, dried with $\mathrm{MgSO}_{4}$, filtered, and concentrated under reduced pressure. The crude product was purified by flash chromatography (PE/EtOAc 60/40 v/v) to give the title compound (1.12 g) as a colourless oil; yield: 38\%. ${ }^{1} \mathrm{H}-\mathrm{NMR}\left(\mathrm{CDCl}_{3}\right)$ d 2.36 (qi, 2H, $\left.-\mathrm{OCH}_{2} \mathrm{CH}_{2}-\right), 2.48$ (t, 4H, $\left.-\mathrm{CH}_{2} \mathrm{NCH}_{2}-\right), 3.53(s$, $\left.2 \mathrm{H},-\mathrm{ArCH}_{2} \mathrm{~N}\right), 3.64-3.73$ (m, 6H, $\left.-\mathrm{CH}_{2} \mathrm{OCH}_{2-},-\mathrm{CH}_{2} \mathrm{Br}\right), 3.89$ (s, 3H, -OCH $\mathrm{O}_{3}, 4.19$ (t, 2H, $-\mathrm{OCH}_{2}$ ), $6.90\left(\mathrm{~d}, 1 \mathrm{H}, \mathrm{C}_{6} \mathrm{H}_{3}\right), 7.94\left(d, 1 \mathrm{H}, \mathrm{C}_{6} \mathrm{H}_{3}\right), 8.01$ (s, 1H, Arom). ${ }^{13} \mathrm{C}-\mathrm{NMR}\left(\mathrm{CDCl}_{3}\right) \mathrm{d} 29.8,32.2,51.9$, $53.7,56.7,65.5,67.0,110.8,122.4,126.1,130.6,132.3,160.6,166.9$.

\section{General procedure for the preparation of nitrooxy derivatives $(7,8,47)$}

A solution of the appropriate bromo/chloro derivative (1.93 mmol) and $\mathrm{AgNO}_{3}(0.82 \mathrm{~g}, 4.82 \mathrm{mmol})$ in $\mathrm{CH}_{3} \mathrm{CN}(15 \mathrm{~mL})$ was stirred at $70{ }^{\circ} \mathrm{C}$ for $14 \mathrm{~h}$. Brine was then added to precipitate the excess of $\mathrm{AgNO}_{3}$, the mixture was filtered through Celite ${ }^{\circledR}$ and concentrated under reduced pressure. The residue was treated with EtOAc $(50 \mathrm{~mL})$ and $\mathrm{H}_{2} \mathrm{O}(50 \mathrm{~mL})$. After separation, the aqueous layer was extracted twice with EtOAc $(10 \mathrm{~mL})$. The combined organic layers were dried with $\mathrm{MgSO}_{4}$, filtered, and concentrated under reduced pressure. The crude product thus obtained was purified, if necessary, by flash chromatography. Chromatographic eluents and yields of the products were as follows. 


\section{3-(4-Formyl-2-hydroxyphenoxy)propyl nitrate (7)}

The crude product was used without any purification as a yellow oil; yield $89 \%$. ${ }^{1} \mathrm{H}-\mathrm{NMR}\left(\mathrm{CDCl}_{3}\right)$ $\delta 2.33$ (qi, $\left.2 \mathrm{H},-\mathrm{OCH}_{2} \mathrm{CH}_{2}-\right), 4.27$ (t, $2 \mathrm{H},-\mathrm{OCH}_{2} \mathrm{CH}_{2}$ ), 4.67 (t, 2H, $-\mathrm{CH}_{2} \mathrm{ONO}_{2}$ ), 5.76 (sbr, 1H, $\mathrm{OH}), 6.97\left(\mathrm{~d}, 1 \mathrm{H}, \mathrm{C}_{6} \mathrm{H}_{3}\right), 7.42\left(\mathrm{~m}, 1 \mathrm{H}, \mathrm{C}_{6} \mathrm{H}_{3}\right), 7.44-7.47\left(\mathrm{~m}, 1 \mathrm{H}, \mathrm{C}_{6} \mathrm{H}_{3}\right), 9.85(\mathrm{~s}, 1 \mathrm{H},-\mathrm{CHO}) .{ }^{13} \mathrm{C}-$ $\operatorname{NMR}\left(\mathrm{CDCl}_{3}\right) \delta 26.9,65.3,69.6,111.1,114.7,124.4,131.1,146.1,150.5,190.8 . \mathrm{MS}(\mathrm{CI}) \mathrm{m} / \mathrm{z} 242$ $(\mathrm{M}+1)^{+}$.

\section{4-(4-Formyl-2-hydroxyphenoxy)butyl nitrate (8)}

The crude product was used without any purification as yellow solid; yield $63 \%$. m.p. 108-108.5 ${ }^{\circ} \mathrm{C}\left(i \mathrm{Pr}_{2} \mathrm{O}\right) .{ }^{1} \mathrm{H}-\mathrm{NMR}\left(\mathrm{CDCl}_{3}\right) \delta$ 1.95-2.04 (m, 4H, $\left.-\mathrm{OCH}_{2} \mathrm{CH}_{2}-\right), 4.20\left(\mathrm{t}, 2 \mathrm{H},-\mathrm{OCH}_{2} \mathrm{CH}_{2}-\right), 4.55(\mathrm{t}$, $\left.2 \mathrm{H},-\mathrm{CH}_{2} \mathrm{ONO}_{2}\right), 5.74(\mathrm{~s}, 1 \mathrm{H}, \mathrm{OH}), 6.96\left(\mathrm{~d}, 1 \mathrm{H}, \mathrm{C}_{6} \mathrm{H}_{3}\right), 7.41-7.46\left(\mathrm{~m}, 2 \mathrm{H}, \mathrm{C}_{6} \mathrm{H}_{3}\right), 9.85(\mathrm{~s}$, $1 \mathrm{H},-\mathrm{CHO}) .{ }^{13} \mathrm{C}-\mathrm{NMR}\left(\mathrm{CDCl}_{3}\right) \delta 23.7,25.5,68.2,72.5,111.0,114.4,124.5,130.8,146.1,150.9$, 191.0. MS (CI) $m / z, 256(\mathrm{M}+1)^{+}$.

\section{Methyl 3-hydroxy-4-(3-nitrooxypropoxy)benzoate (27)}

The crude product was crystallized with toluene to give the title compound as a pale yellow solid; yield $68 \%$. m.p. $76.5-77{ }^{\circ} \mathrm{C}$ (toluene). ${ }^{1} \mathrm{H}-\mathrm{NMR}\left(\mathrm{CDCl}_{3}\right) \delta 2.28\left(\mathrm{qi}, 2 \mathrm{H},-\mathrm{OCH}_{2} \mathrm{CH}_{2^{-}}\right.$), 3.88 (s, 3H, $\left.\mathrm{OCH}_{3}\right), 4.23\left(\mathrm{t}, 2 \mathrm{H},-\mathrm{OCH}_{2} \mathrm{CH}_{2}\right), 4.67\left(\mathrm{t}, 2 \mathrm{H},-\mathrm{CH}_{2} \mathrm{ONO}_{2}\right), 5.50(\mathrm{svbr}, 1 \mathrm{H}, \mathrm{OH}), 6.87(\mathrm{~d}, 1 \mathrm{H}$, $\left.\mathrm{C}_{6} \mathrm{H}_{3}\right), 7.59-7.61\left(\mathrm{~m}, 2 \mathrm{H}, \mathrm{C}_{6} \mathrm{H}_{3}\right) .{ }^{13} \mathrm{C}-\mathrm{NMR}\left(\mathrm{CDCl}_{3}\right) \delta 26.9,52.0,65.0,69.7,110.8,116.1,122.8$, 123.9, 145.2, 149.2, 166.7. MS (CI) $m / z 272(\mathrm{M}+1)^{+}$.

\section{Methyl 3-(morpholin-4-ylmethyl)-4-[3-(nitrooxy)propoxy]benzoate (47)}

Eluent: PE/EtOAc 60/40 v/v; colourless oil; yield: 75\%. ${ }^{1} \mathrm{H}-\mathrm{NMR}\left(\mathrm{CDCl}_{3}\right)$ d 2.27 (qi, 2H, $\mathrm{OCH}_{2} \mathrm{CH}_{2^{-}}$), 2.49 (m, 4H,- $\mathrm{CH}_{2} \mathrm{NCH}_{2^{-}}$), 3.53 (s, 2H, - $\left.\mathrm{NCH}_{2} \mathrm{Ar}\right), 3.70$ (m, 4H, - $\mathrm{CH}_{2} \mathrm{OCH}_{2^{-}}$), 3.89 (s, $\left.3 \mathrm{H},-\mathrm{OCH}_{3}\right), 4.15$ (t, $\left.2 \mathrm{H},-\mathrm{OCH}_{2}-\right), 4.72$ (t, 2H, $\left.-\mathrm{CH}_{2} \mathrm{ONO}_{2}\right), 6.87\left(\mathrm{~d}, 1 \mathrm{H}, \mathrm{C}_{6} \mathrm{H}_{3}\right), 7.94\left(\mathrm{~d}, 1 \mathrm{H}, \mathrm{C}_{6} \mathrm{H}_{3}\right)$, $8.02\left(\mathrm{~s}, 1 \mathrm{H}, \mathrm{C}_{6} \mathrm{H}_{3}\right) .{ }^{13} \mathrm{C}-\mathrm{NMR}\left(\mathrm{CDCl}_{3}\right) \mathrm{d} 27.0,51.9,53.7,56.7,63.9,67.0,69.8,110.7,122.6,126.1$, 130.6, 132.4, 160.4, 166.9.

\section{General procedure for the preparation of N-BOC-protected derivatives $(9-14,22)$}

To a solution of BOC-protected aminoacid $(9.38 \mathrm{mmol})$ in dry $\mathrm{CH}_{2} \mathrm{Cl}_{2}(60 \mathrm{~mL})$, stirred under inert atmosphere, $\mathrm{EDC} \cdot \mathrm{HCl}(3.96 \mathrm{~g} ; 20.66 \mathrm{mmol})$ and DMAP (0.12 g; $0.92 \mathrm{mmol})$ were added. After 30 min the appropriate phenol derivative $(1.70 \mathrm{~g} ; 7.05 \mathrm{mmol})$ was added. The reaction was completed after 3 hours The reaction mixture was washed with $\mathrm{H}_{2} \mathrm{O}(50 \mathrm{~mL})$, dried, filtered, and concentrated under reduced pressure. The crude product thus obtained was purified by flash chromatography. Chromatographic eluents and yields of the products were as follows.

\section{5-Formyl-2-[(nitrooxy)propoxy]-phenyl-3-[(tert-butoxycarbonyl)amino]propanoate (9)}


Eluent: PE/EtOAc 80/20 v/v; yellow solid; yield: $70 \%$. m.p. 80.7-83 ${ }^{\circ} \mathrm{C}\left(i \mathrm{Pr}_{2} \mathrm{O}\right) .{ }^{1} \mathrm{H}-\mathrm{NMR}\left(\mathrm{CDCl}_{3}\right)$ $\delta 1.46(\mathrm{~s}, 9 \mathrm{H}, t-\mathrm{Bu}), 2.25$ (qi, 2H, $-\mathrm{OCH}_{2} \mathrm{CH}_{2-}$ ), $2.84\left(\mathrm{t}, 2 \mathrm{H},-\mathrm{CH}_{2} \mathrm{CH}_{2} \mathrm{NH}-\right), 3.52-3.54(\mathrm{~m}, 2 \mathrm{H},-$ $\left.\mathrm{CH}_{2} \mathrm{CH}_{2} \mathrm{NH}-\right), 4.21\left(\mathrm{t}, 2 \mathrm{H},-\mathrm{OCH}_{2} \mathrm{CH}_{2}-\right), 4.62\left(\mathrm{t}, 2 \mathrm{H},-\mathrm{CH}_{2} \mathrm{ONO}_{2}\right), 5.11(\mathrm{sbr}, 1 \mathrm{H},-\mathrm{NH}), 7.08(\mathrm{~d}, 1 \mathrm{H}$,

$\left.\mathrm{C}_{6} \mathrm{H}_{3}\right), 7.62\left(\mathrm{~m}, 1 \mathrm{H}, \mathrm{C}_{6} \mathrm{H}_{3}\right), 7.75-7.79\left(\mathrm{~m}, 1 \mathrm{H}, \mathrm{C}_{6} \mathrm{H}_{3}\right), 9.87(\mathrm{~s}, 1 \mathrm{H},-\mathrm{CHO}) .{ }^{13} \mathrm{C}-\mathrm{NMR}\left(\mathrm{CDCl}_{3}\right) \delta$ 26.8, 28.4, 34.5, 36.1, 64.9, 69.4, 79,7, 112.7, 123.5, 130.2, 130.4, 140.1, 154.9, 155.8, 170.0, 189.9. MS (CI) $m / z, 413(\mathrm{M}+1)^{+}$.

\section{5-Formyl-2-[(nitrooxy)butoxy]-phenyl-3-[(tert-butoxycarbonyl)amino]propano (10)}

Eluent: PE/EtOAc 80/20 v/v; yellow oil; yield: $48 \% .{ }^{1} \mathrm{H}-\mathrm{NMR}\left(\mathrm{CDCl}_{3}\right) \delta 1.46(\mathrm{~s}, 9 \mathrm{H}, t$-Bu), 1.89 $1.978\left(\mathrm{~m}, 4 \mathrm{H},-\mathrm{OCH}_{2} \mathrm{CH}_{2} \mathrm{CH}_{2-}\right.$ ), 2.83 (t, $\left.2 \mathrm{H},-\mathrm{CH}_{2} \mathrm{CH}_{2} \mathrm{NH}-\right), 3.50-3.56\left(\mathrm{~m}, 2 \mathrm{H},-\mathrm{CH}_{2} \mathrm{CH}_{2} \mathrm{NH}-\right), 4.13$ (t, $\left.2 \mathrm{H},-\mathrm{OCH}_{2} \mathrm{CH}_{2}-\right), 4.53\left(\mathrm{t}, 2 \mathrm{H},-\mathrm{CH}_{2} \mathrm{ONO}_{2}\right), 5.02(\mathrm{~m}, 1 \mathrm{H}, \mathrm{NH}), 7.06\left(\mathrm{~d}, 1 \mathrm{H}, \mathrm{C}_{6} \mathrm{H}_{3}\right), 7.61-7.62(\mathrm{~m}$, $\left.1 \mathrm{H}, \mathrm{C}_{6} \mathrm{H}_{3}\right), 7.75-7.78\left(\mathrm{~m}, 1 \mathrm{H}, \mathrm{C}_{6} \mathrm{H}_{3}\right), 9.88(\mathrm{~s}, 1 \mathrm{H},-\mathrm{CHO}) .{ }^{13} \mathrm{C}-\mathrm{NMR}\left(\mathrm{CDCl}_{3}\right) \delta$ 23.6, 25.3, 28.4, $34.5,36.2$, 68.1, 72.5, 79.6, 112.7, 123.5, 130.1, 130.2, 140.1, 155.2, 155.8, 170.1, 189.9. MS (CI) $m / z, 427(\mathrm{M}+1)^{+}$.

\section{5-Formyl-2-[(nitrooxy)propoxy]-phenyl-3-[(tert-butoxycarbonyl)amino]acetate (11)}

Eluent: PE/EtOAc 80/20 v/v; white solid; yield: $50 \%$. m.p. $97-98{ }^{\circ} \mathrm{C}\left(i \mathrm{Pr}_{2} \mathrm{O}\right) .{ }^{1} \mathrm{H}-\mathrm{NMR}\left(\mathrm{CDCl}_{3}\right) \delta$ $1.47(\mathrm{~s}, 9 \mathrm{H}, t-\mathrm{Bu}), 2.25$ (qi, $\left.2 \mathrm{H},-\mathrm{OCH}_{2} \mathrm{CH}_{2}-\right)$, 4.17-4.22 (m, $\left.4 \mathrm{H},-\mathrm{CH}_{2} \mathrm{NH}-+-\mathrm{OCH}_{2} \mathrm{CH}_{2}-\right), 4.64(\mathrm{t}$, $\left.2 \mathrm{H},-\mathrm{CH}_{2} \mathrm{ONO}_{2}\right), 5.10(\mathrm{~m}, 1 \mathrm{H}, \mathrm{NH}), 7.07\left(\mathrm{~d}, 1 \mathrm{H}, \mathrm{C}_{6} \mathrm{H}_{3}\right), 7.61-7.62\left(\mathrm{~m}, 1 \mathrm{H}, \mathrm{C}_{6} \mathrm{H}_{3}\right), 7.76-7.79(\mathrm{~m}, 1 \mathrm{H}$, $\left.\mathrm{C}_{6} \mathrm{H}_{3}\right), 9.87$ (s, 1H, -CHO). ${ }^{13} \mathrm{C}-\mathrm{NMR}\left(\mathrm{CDCl}_{3}\right) \delta 26.8,28.3,42.1,64.9,69.6,80.3,112.7,123.3$, 130.3, 139.9, 154.9, 155.7, 168.4, 189.8. MS (CI) $m / z 399(\mathrm{M}+1)^{+}$.

\section{5-Formyl-2-[(nitrooxy)propoxy]-phenyl-3-[(tert-butoxycarbonyl)amino]butanoate (12)}

Eluent: PE/EtOAc 70/30 v/v; white solid; yield: $85 \%$. m.p. 71.5-72.5 ${ }^{\circ} \mathrm{C}\left(\mathrm{iPr}_{2} \mathrm{O}\right) .{ }^{1} \mathrm{H}-\mathrm{NMR}\left(\mathrm{CDCl}_{3}\right)$ $\delta 1.46(\mathrm{~s}, 9 \mathrm{H}, t-\mathrm{Bu}), 1.95$ (qi, 2H, $-\mathrm{CH}_{2} \mathrm{CH}_{2} \mathrm{NH}-$ ), 2.25 (qi, 2H, $-\mathrm{OCH}_{2} \mathrm{CH}_{2}$ ), 2.66 (t, 2H, $\left.\mathrm{COCH}_{2} \mathrm{CH}_{2}-\right), 3.23-3.30\left(\mathrm{~m}, 2 \mathrm{H},-\mathrm{CH}_{2} \mathrm{CH}_{2} \mathrm{NH}-\right), 4.20\left(\mathrm{t}, 2 \mathrm{H},-\mathrm{OCH}_{2} \mathrm{CH}_{2}-\right), 4.62(\mathrm{t}, 2 \mathrm{H},-$ $\mathrm{CH}_{2} \mathrm{ONO}_{2}$ ), 4.70 (sbr, $\left.1 \mathrm{H}, \mathrm{NH}\right), 7.07\left(\mathrm{~d}, 1 \mathrm{H}, \mathrm{C}_{6} \mathrm{H}_{3}\right), 7.60-7.61\left(\mathrm{~m}, 1 \mathrm{H}, \mathrm{C}_{6} \mathrm{H}_{3}\right), 7.75-7.78(\mathrm{~m}, 1 \mathrm{H}$, $\left.\mathrm{C}_{6} \mathrm{H}_{3}\right), 9.88$ (s, 1H, -CHO). ${ }^{13} \mathrm{C}-\mathrm{NMR}\left(\mathrm{CDCl}_{3}\right) \delta 25.4,26.8,28.4,31.1,39.8,64.8,69.5,79.4,112.7$, 123.6, 130.1, 130.3, 140.2, 155.0, 156.0, 170.9, 190.0. MS (CI) $m / z 427(\mathrm{M}+1)^{+}$.

\section{5-Formyl-2-[(nitrooxy)propoxy]-phenyl-2-[(tert-butoxycarbonyl)amino]propanoate (13)}

Eluent: PE/EtOAc 70/30 v/v; white solid; yield: $65 \% .93 .5{ }^{\circ} \mathrm{C}$ darkening/fuming, m.p. 102 ${ }^{\circ} \mathrm{C}\left(\mathrm{iPr}_{2} \mathrm{O}\right) .{ }^{1} \mathrm{H}-\mathrm{NMR}\left(\mathrm{CDCl}_{3}\right) \delta 1.47$ (s, 9H, t-Bu), 1.57 (d, 3H, - $\left.\mathrm{CHCH}_{3}\right), 2.24$ (qi, 2H, - $\mathrm{OCH}_{2} \mathrm{CH}_{2}-$ ), $4.19\left(\mathrm{t}, 2 \mathrm{H},-\mathrm{OCH}_{2} \mathrm{CH}_{2}-\right), 4.58-4.66\left(\mathrm{~m}, 3 \mathrm{H},-\mathrm{CHCH}_{3}+-\mathrm{CH}_{2} \mathrm{ONO}_{2}\right), 5.05-5.08(\mathrm{~m}, 1 \mathrm{H}, \mathrm{NH}), 7.07$ $\left(\mathrm{d}, 1 \mathrm{H}, \mathrm{C}_{6} \mathrm{H}_{3}\right), 7.61-7.62\left(\mathrm{~m}, 1 \mathrm{H}, \mathrm{C}_{6} \mathrm{H}_{3}\right), 7.76-7.79\left(\mathrm{~m}, 1 \mathrm{H}, \mathrm{C}_{6} \mathrm{H}_{3}\right), 9.88(\mathrm{~s}, 1 \mathrm{H},-\mathrm{CHO}) .{ }^{13} \mathrm{C}-\mathrm{NMR}$ $\left(\mathrm{CDCl}_{3}\right) \delta 18.5,26.8,28.3,49.2,64.7,69.4,80.1,110.7,112.7,123.4,130.3,140.0,155.0,171.2$, 189.8. MS (CI) $m / z, 413(\mathrm{M}+1)^{+}$. 


\section{5-Formyl-2-[(nitrooxypropoxy)-phenyl-2-(tert-butoxycarbonylamino)-3-(tert-butyl- dimethylsyliloxy)butanoate (14)}

Eluent: PE/EtOAc 90/10 v/v; colourless oil; yield: $29 \% .{ }^{1} \mathrm{H}-\mathrm{NMR}\left(\mathrm{CDCl}_{3}\right) \delta 0.11\left(s, 3 \mathrm{H}, \mathrm{CH}_{3} \mathrm{Si}-\right)$, $0.12\left(s, 3 \mathrm{H}, \mathrm{CH}_{3} \mathrm{Si}-\right), 0.90(s, 9 \mathrm{H}, t \mathrm{BuSi}), 1.31$ ( $\left.s, 3 \mathrm{H},-\mathrm{CHCH}_{3}\right), 1.47(s, 9 \mathrm{H}, t \mathrm{BuO}-), 2.25$ ( $q, 2 \mathrm{H},-$ $\left.\mathrm{OCH}_{2} \mathrm{CH}_{2-}\right), 4.16\left(t, 2 \mathrm{H},-\mathrm{OCH}_{2} \mathrm{CH}_{2-}\right), 4.45-4.49(m, 1 \mathrm{H},-\mathrm{CHNH}-), 4.60-4.72\left(m, 3 \mathrm{H},-\mathrm{CH}_{2} \mathrm{ONO}_{2}\right.$ +-CHOSi-), 5.25-5.30 (m, 1H, -NH-), $7.07\left(d, 1 \mathrm{H}, \mathrm{C}_{6} \mathrm{H}_{3}\right), 7.60-7.61\left(m, 1 \mathrm{H}, \mathrm{C}_{6} \mathrm{H}_{3}\right), 7.74-7.78(m$, $\left.1 \mathrm{H}, \mathrm{C}_{6} \mathrm{H}_{3}\right), 9.87(s, 1 \mathrm{H},-\mathrm{CHO}) .{ }^{13} \mathrm{C}-\mathrm{NMR}\left(\mathrm{CDCl}_{3}\right) \delta-4.9,-4.1,18.0,21.0,25.7,26.7,28.3,59.5$, 64.7, 68.7, 69.6, 80.0, 112.8, 122.8, 130.2, 140.4, 155.0, 156.1, 169.2, 189.8 .

\section{2-(Allyloxy)-5-formylphenyl 3-[(tert-butoxycarbonyl)amino]propanoate (22)}

Eluent: PE/EtOAc 90/10 v/v to 80/20; colourless oil; yield: $56 \% .{ }^{1} \mathrm{H}-\mathrm{NMR}\left(\mathrm{CDCl}_{3}\right) \delta 1.46(\mathrm{~s}, 9 \mathrm{H}$, $t$-Bu), 2.82 (t, 2H, - $\mathrm{CH}_{2} \mathrm{CH}_{2} \mathrm{NH}-$ ), 3.53-3.58 (m, 2H, $-\mathrm{CH}_{2} \mathrm{CH}_{2} \mathrm{NH}-$ ), 4.67-4.68 (m, 2H, -OCH $2^{-}$), 5.17 (svbr, 1H, -NH), 5.32-5.43 (m, AMX like system, 2H, - $\mathrm{CH}=\mathrm{CH}_{2}$ ), 5.95-6.08 (m, AMX like system, $\left.1 \mathrm{H},-\mathrm{CH}=\mathrm{CH}_{2}\right), 7.07\left(\mathrm{~d}, 1 \mathrm{H}, \mathrm{C}_{6} \mathrm{H}_{3}\right), 7.61-7.62\left(\mathrm{~m}, 1 \mathrm{H}, \mathrm{C}_{6} \mathrm{H}_{3}\right), 7.73-7.76\left(\mathrm{~m}, 1 \mathrm{H}, \mathrm{C}_{6} \mathrm{H}_{3}\right), 9.87$ (s, 1H, -CHO). ${ }^{13} \mathrm{C}-\mathrm{NMR}\left(\mathrm{CDCl}_{3}\right) \delta 28.4,31.1,33.8,34.7,36.2,69.6,79.5,113.2,118.9,123.5$, 130.1, 131.6, 140.2, 155.0, 190.0. MS (CI) $m / z, 350(\mathrm{M}+1)^{+}$.

\section{2-[2,3-Bis(nitrooxy)propyl]-5-formylphenyl 3-[(tert-butoxycarbonyl)amino]propanoate (23)}

Iodine $(0.70 \mathrm{~g}, 2.78 \mathrm{mmol})$ was added portionwise to a stirred solution of $22(0.97 \mathrm{~g}, 2.78 \mathrm{mmol})$ plus $\mathrm{AgNO}_{3}(0.47 \mathrm{~g}, 2.78 \mathrm{mmol})$ in $\mathrm{CH}_{3} \mathrm{CN}(10 \mathrm{~mL}) \mathrm{kept}$ at $-15^{\circ} \mathrm{C}$. At the end of the addition, stirring was continued for $1 \mathrm{~h} . \mathrm{AgNO}_{3}(1.18 \mathrm{~g}, 6.95 \mathrm{mmol})$ was then added and the mixture heated to $70{ }^{\circ} \mathrm{C}$ for $16 \mathrm{~h}$. After cooling, the mixture was filtered through Celite ${ }^{\circledR}$. The filtrate was concentrated under reduced pressure, dissolved in water $(40 \mathrm{~mL})$ and extracted with EtOAc $(3 \times 20$ $\mathrm{mL})$. The combined organic layers were washed with brine $(20 \mathrm{~mL})$, dried with $\mathrm{MgSO}_{4}$, filtered, and concentrated under reduced pressure. The crude product was purified by flash chromatography (PE/EtOAc 80/20 v/v) to give the title compound as a yellow oil; yield: $31 \% .{ }^{1} \mathrm{H}-\mathrm{NMR}\left(\mathrm{CDCl}_{3}\right) \delta$ $1.46(\mathrm{~s}, 9 \mathrm{H}, t-\mathrm{Bu}), 2.84\left(\mathrm{t}, 2 \mathrm{H},-\mathrm{CH}_{2} \mathrm{CH}_{2} \mathrm{NH}-\right), 3.51-3.56\left(\mathrm{~m}, 2 \mathrm{H},-\mathrm{CH}_{2} \mathrm{CH}_{2} \mathrm{NH}-\right), 4.38(\mathrm{~d}, 2 \mathrm{H},-$ $\mathrm{OCH}_{2} \mathrm{CH}-$ ), 4.69-4.90 (m, AMX-like system, 2H, $-\mathrm{CHCH}_{2} \mathrm{ONO}_{2}$ ), 5.03 (svbr, 1H, -NH), 5.62-5.66 (m, AMX-like system, 1H, - $\left.\mathrm{CHCH}_{2} \mathrm{ONO}_{2}\right), 7.08\left(\mathrm{~d}, 1 \mathrm{H}, \mathrm{C}_{6} \mathrm{H}_{3}\right), 7.64-7.65\left(\mathrm{~m}, 1 \mathrm{H}, \mathrm{C}_{6} \mathrm{H}_{3}\right)$, 7.76-7.81 $\left(\mathrm{m}, 1 \mathrm{H}, \mathrm{C}_{6} \mathrm{H}_{3}\right), 9.90$ (s, $\left.1 \mathrm{H},-\mathrm{CHO}\right) .{ }^{13} \mathrm{C}-\mathrm{NMR}\left(\mathrm{CDCl}_{3}\right) \delta 14.2,27.9,28.4,34.5,36.0,60.5,65.8$, 68.4, 70.0, 113.0, 123.9, 130.0, 131.3, 140.2, 153.9, 155.9, 179.9, 189.8. MS (CI) $m / z$. $473(\mathrm{M}+1)^{+}$.

\section{General procedure for the preparation of carboxylic acid from aldehyde (15-20, 24)}

$\mathrm{KMnO}_{4}(0.52 \mathrm{~g}, 3.27 \mathrm{mmol})$ was added to a solution of the appropriate aldehyde $(2.18 \mathrm{mmol})$ in acetone $(50 \mathrm{~mL})$, and stirred at $0{ }^{\circ} \mathrm{C}$. The reaction was allowed to reach r.t.; it was complete after $1 \mathrm{~h}$ (TLC detection, eluent $\mathrm{CH}_{2} \mathrm{Cl}_{2} / \mathrm{MeOH} 95 / 5 \mathrm{v} / \mathrm{v}$ ). Oxalic acid was added and the mixture was filtered and the filtrate was diluted with $\mathrm{CH}_{2} \mathrm{Cl}_{2}(100 \mathrm{~mL})$. The organic layer was washed twice 
with $\mathrm{H}_{2} \mathrm{O}(50 \mathrm{~mL})$, then dried with $\mathrm{MgSO}_{4}$, filtered, and concentrated under reduced pressure to give the desired product.

3-(\{3-[(tert-Butoxycarbonyl)amino]propanoyl $\} o x y)-4-[($ nitrooxy)propoxy]benzoic acid (15)

White solid; yield $96 \%$. m.p. 123-126 ${ }^{\circ} \mathrm{C}$ (Toluene). ${ }^{1} \mathrm{H}-\mathrm{NMR}$ (DMSO-d 6 ) $\delta 1.46$ (s, 9H, $t$-Bu), 2.15 (qi, 2H, $-\mathrm{OCH}_{2} \mathrm{CH}_{2}$ ), 2.73 (t, $2 \mathrm{H},-\mathrm{CH}_{2} \mathrm{CH}_{2} \mathrm{NH}-$ ), 3.10-3.17 (m, 2H, $-\mathrm{CH}_{2} \mathrm{CH}_{2} \mathrm{NH}-$ ), 4.17 (t, $\left.2 \mathrm{H},-\mathrm{OCH}_{2} \mathrm{CH}_{2}-\right), 4.61\left(\mathrm{t}, 2 \mathrm{H},-\mathrm{CH}_{2} \mathrm{ONO}_{2}\right), 6.97-5.00(\mathrm{~m}, 1 \mathrm{H},-\mathrm{NH}), 7.23\left(\mathrm{~d}, 1 \mathrm{H}, \mathrm{C}_{6} \mathrm{H}_{3}\right), 7.70(\mathrm{~m}$, $1 \mathrm{H}, \mathrm{C}_{6} \mathrm{H}_{3}$ ), 7.83-7.87 (m, 1H, $\mathrm{C}_{6} \mathrm{H}_{3}$ ), 12.8 (svvbr, 1H, -COOH). ${ }^{13} \mathrm{C}-\mathrm{NMR}$ (DMSO-d ${ }_{6}$ ) $\delta 26.0,28.1$, $33.9,36.0,64.9,70.5,77.8,113.0,123.3,124.0,128.7,138.9,153.5,155.5,166.3,169.3$. MS (CI) $m / z, 29(\mathrm{M}+1)^{+}$.

\section{3-(\{3-[(tert-Butoxycarbonyl)amino]propanoyl\}oxy)-4-[(nitrooxy)butoxy]benzoic acid (16)}

White solid; yield $90 \%$. m.p. $102{ }^{\circ} \mathrm{C}$ (toluene). ${ }^{1} \mathrm{H}-\mathrm{NMR}$ (DMSO-d 6$) \delta 1.39$ (s, 9H, $t$-Bu), 1.79 $1.83\left(\mathrm{~m}, 4 \mathrm{H},-\mathrm{OCH}_{2} \mathrm{CH}_{2} \mathrm{CH}_{2}-\right), 2.71$ (t, 3H, $\left.-\mathrm{CH}_{2} \mathrm{CH}_{2} \mathrm{NH}-\right), 3.26-3.33\left(\mathrm{~m}, 2 \mathrm{H},-\mathrm{CH}_{2} \mathrm{CH}_{2} \mathrm{NH}-\right), 4.11$ $\left(\mathrm{t}, 2 \mathrm{H},-\mathrm{OCH}_{2} \mathrm{CH}_{2}-\right), 4.57\left(\mathrm{t}, 2 \mathrm{H},-\mathrm{CH}_{2} \mathrm{ONO}_{2}\right), 6.97-7.01(\mathrm{~m}, 1 \mathrm{H}, \mathrm{NH}), 7.21\left(\mathrm{~d}, 1 \mathrm{H}, \mathrm{C}_{6} \mathrm{H}_{3}\right), 7.67-$ $7.68\left(\mathrm{~m}, 1 \mathrm{H}, \mathrm{C}_{6} \mathrm{H}_{3}\right), 7.82-7.85\left(\mathrm{~d}, 1 \mathrm{H}, \mathrm{C}_{6} \mathrm{H}_{3}\right), 12.8$ (sbr, $\left.1 \mathrm{H},-\mathrm{COOH}\right) .{ }^{13} \mathrm{C}-\mathrm{NMR}$ (DMSO-d 6 ) $\delta 22.7$, 24.6, 28.1, 33.9, 36.0, 67.7, 73.3, 77.7, 113.0, 123.0, 123.9, 128.7, 138.8, 153.7, 155.4, 166.3, 169.2. MS (CI) m/z $443(\mathrm{M}+1)^{+}$.

\section{3-(\{3-[(tert-Butoxycarbonyl)amino]acetoxy $\})-4-[($ nitrooxy $)$ propoxy $]$ benzoic acid (17)}

White solid; yield $50 \%$. m.p. 158.5-159 ${ }^{\circ} \mathrm{C}$ (Toluene). ${ }^{1} \mathrm{H}-\mathrm{NMR}$ (DMSO-d 6 ) $\delta 1.40$ (s, 9H, $t$-Bu), 2.09-2.16 (m, 2H, - $\left.\mathrm{OCH}_{2} \mathrm{CH}_{2}-\right)$, 3.99-4.01 (m, 2H, $\left.-\mathrm{CH}_{2} \mathrm{NH}-\right), 4.16\left(\mathrm{t}, 2 \mathrm{H},-\mathrm{OCH}_{2} \mathrm{CH}_{2}-\right), 4.66$ (t, $\left.2 \mathrm{H},-\mathrm{CH}_{2} \mathrm{ONO}_{2}\right), 7.26\left(\mathrm{~d}, 1 \mathrm{H}, \mathrm{C}_{6} \mathrm{H}_{3}\right), 7.61-7.62\left(\mathrm{~m}, 1 \mathrm{H}, \mathrm{C}_{6} \mathrm{H}_{3}\right), 7.84-7.87\left(\mathrm{~m}, 1 \mathrm{H}, \mathrm{C}_{6} \mathrm{H}_{3}\right), 12.0$ (sbr, $1 \mathrm{H},-\mathrm{COOH}) .{ }^{13} \mathrm{C}-\mathrm{NMR}\left(\mathrm{DMSO}-\mathrm{d}_{6}\right) \delta 26.9,28.9,42.5,65.7,71.5,79.3,114.1,124.2,124.4,129.8$, 139.7, 154.4, 156.7, 167.1, 169.6. MS (CI) $m / z, 415(\mathrm{M}+1)^{+}$.

\section{3-(\{3-[(tert-Butoxycarbonyl)amino]butanoyl\}oxy)-4-[(nitrooxy)propoxy]benzoic acid (18)}

White solid; yield $75 \%$. m.p. 138-140 ${ }^{\circ} \mathrm{C}$ (Toluene). ${ }^{1} \mathrm{H}-\mathrm{NMR}\left(\mathrm{CDCl}_{3}\right) \delta 1.46$ (s, 9H, $t$-Bu), 1.95 (qi, 2H, - $\mathrm{CH}_{2} \mathrm{CH}_{2} \mathrm{NH}-$ ), 2.23 (qi, 2H, $-\mathrm{OCH}_{2} \mathrm{CH}_{2}$ ), 2.66 (t, $2 \mathrm{H},-\mathrm{COCH}_{2} \mathrm{CH}_{2}$ ), 3.24-3.30 (m, 2H, $\left.\mathrm{CH}_{2} \mathrm{CH}_{2} \mathrm{NH}-\right), 4.18$ (t, $\left.2 \mathrm{H},-\mathrm{OCH}_{2} \mathrm{CH}_{2}-\right), 4.61$ (t, 2H, $\left.-\mathrm{CH}_{2} \mathrm{ONO}_{2}\right), 4.70$ (sbr, $\left.1 \mathrm{H}, \mathrm{NH}\right), 6.99$ (d, 1H, $\left.\mathrm{C}_{6} \mathrm{H}_{3}\right), 7.79\left(\mathrm{~s}, 1 \mathrm{H}, \mathrm{C}_{6} \mathrm{H}_{3}\right), 8.00\left(\mathrm{~d}, 1 \mathrm{H}, \mathrm{C}_{6} \mathrm{H}_{3}\right) .{ }^{13} \mathrm{C}-\mathrm{NMR}\left(\mathrm{CDCl}_{3}\right) \delta$ 25.4, 26.8, 28.4, 29.7, 31.1, 64.6, 69.5, 82.3 112.3, 122.4, 125.1, 129.8, 139.4, 154.4, 169.6, 170.9. MS (CI) $m / z 443(\mathrm{M}+1)^{+}$.

\section{3-(\{2-[(tert-Butoxycarbonyl)amino]propanoyl $\}$ oxy $)-4-[($ nitrooxy $)$ propoxy]benzoic acid (19)}

White solid; yield $80 \%$. m.p. 133-134 ${ }^{\circ} \mathrm{C}$ (Toluene). ${ }^{1} \mathrm{H}-\mathrm{NMR}$ (DMSO-d 6$) \delta{ }^{1} \mathrm{H}-\mathrm{NMR}\left(\mathrm{CDCl}_{3}\right) \delta$ 1.41-1.43 (m, $\left.12 \mathrm{H}, \mathrm{t}-\mathrm{Bu}+-\mathrm{CHCH}_{3}\right), 2.13\left(\mathrm{qi}, 2 \mathrm{H},-\mathrm{OCH}_{2} \mathrm{CH}_{2-}\right), 4.16\left(\mathrm{t}, 2 \mathrm{H},-\mathrm{OCH}_{2} \mathrm{CH}_{2}-\right)$, 4.24$4.30\left(\mathrm{~m}, 1 \mathrm{H},-\mathrm{CHCH}_{3}\right), 4.65\left(\mathrm{t}, 2 \mathrm{H},-\mathrm{CH}_{2} \mathrm{ONO}_{2}\right), 7.25\left(\mathrm{~d}, 1 \mathrm{H}, \mathrm{C}_{6} \mathrm{H}_{3}\right), 7.51-7.57\left(\mathrm{~m}, 2 \mathrm{H}, \mathrm{C}_{6} \mathrm{H}_{3}+\right.$ $\mathrm{NH}), 7.84-7.87\left(\mathrm{~m}, 1 \mathrm{H}, \mathrm{C}_{6} \mathrm{H}_{3}\right), 12.91$ (sbr, $\left.1 \mathrm{H},-\mathrm{COOH}\right) .{ }^{13} \mathrm{C}-\mathrm{NMR}$ (DMSO-d $) \delta$ 16.6, 25.9, 28.1, 
49.0, 64.7, 70.4, 78.3, 113.0, 123.3, 123.5, 128.8, 138.7, 153.5, 155.2, 166.2, 171.3. MS (CI) $\mathrm{m} / \mathrm{z}$ $429(\mathrm{M}+1)^{+}$.

\section{3-[3-(tert-butoxycarbonylamino)(tert-butyl-dimethylsyliloxy)butoxy]-4-} (nitrooxypropoxy)benzoic acid (20)

Colourless oil; yield $71 \% .{ }^{1} \mathrm{H}-\mathrm{NMR}\left(\mathrm{CDCl}_{3}\right) \delta 0.12\left(s, 3 \mathrm{H}, \mathrm{CH}_{3} \mathrm{Si}-\right), 0.13\left(s, 3 \mathrm{H}, \mathrm{CH}_{3} \mathrm{Si}-\right), 0.84(s$, $9 \mathrm{H}, t \mathrm{BuSi}-), 1.35\left(d, 3 \mathrm{H},-\mathrm{CHCH}_{3}\right), 1.48(s, 9 \mathrm{H}, t \mathrm{BuO}-), 2.22\left(q i, 2 \mathrm{H},-\mathrm{OCH}_{2} \mathrm{CH}_{2}-\right), 4.16(t, 2 \mathrm{H},-$ $\left.\mathrm{OCH}_{2} \mathrm{CH}_{2}-\right), 4.48-4.52(m, 1 \mathrm{H},-\mathrm{CHNH}-), 4.61-4.69\left(m, 3 \mathrm{H},-\mathrm{CH}_{2} \mathrm{ONO}_{2}+-\mathrm{CHOSi}-\right), 5.31(d, 1 \mathrm{H},-$ $\mathrm{NH}-), 6.99\left(d, 1 \mathrm{H}, \mathrm{C}_{6} \mathrm{H}_{3}\right), 7.81-7.82\left(m, 1 \mathrm{H}, \mathrm{C}_{6} \mathrm{H}_{3}\right), 7.98-8.02\left(m, 1 \mathrm{H}, \mathrm{C}_{6} \mathrm{H}_{3}\right), 9.86(s b r, 1 \mathrm{H},-\mathrm{CHO})$. ${ }^{13} \mathrm{C}-\mathrm{NMR}\left(\mathrm{CDCl}_{3}\right) \delta-4.9,-4.1,18.4,21.0,25.7,26.7,28.3,59.5,64.6,68.7,69.7,80.0,112.4$, 122.4, 124.5, 130.0, 139.5, 154.4, 156.1, 169.2, 170.6. MS (CI) $m / z 574(\mathrm{M}+1)^{+}$.

4-[2,3-bis(nitrooxy)propyl]-3-(\{3-[(tert-butoxycarbonyl)amino]propanoyl\}oxy)benzoic acid (24)

Pale yellow oil; yield $90 \% .{ }^{1} \mathrm{H}-\mathrm{NMR}\left(\mathrm{DMSO}_{6}\right) \delta 1.36$ (s, 9H, $t$-Bu), $2.70\left(\mathrm{q}, 2 \mathrm{H},-\mathrm{CH}_{2} \mathrm{CH}_{2} \mathrm{NH}-\right.$ ), 4.41-4.49 (m, 2H, -OCH $\mathrm{CH}_{2}$ ), 4.81-5.01 (m, AMX like system, 2H, - $\mathrm{CHCH}_{2} \mathrm{ONO}_{2}$ ), 5.75-5.85 (m, AMX-like system, $\left.1 \mathrm{H},-\mathrm{CHCH}_{2} \mathrm{ONO}_{2}\right), 6.98(\mathrm{t}, 1 \mathrm{H},-\mathrm{NH}), 7.24\left(\mathrm{~d}, 1 \mathrm{H}, \mathrm{C}_{6} \mathrm{H}_{3}\right), 7.38(\mathrm{sbr}, 1 \mathrm{H}$, $\mathrm{COOH}$ ), 7.69-7.70 (m, 1H, $\left.\mathrm{C}_{6} \mathrm{H}_{3}\right), 7.81-7.85\left(\mathrm{~m}, 1 \mathrm{H}, \mathrm{C}_{6} \mathrm{H}_{3}\right) .{ }^{13} \mathrm{C}-\mathrm{NMR}$ (DMSO-d 6 ) $\delta$ 29.3, 35.0, $36.9,50.7,66.8,70.5,78.4,114.2,116.2$, 125.1, 129.6, 139.8, 153.7, 163.4, 167.1, 169.6. MS (CI) $m / z 490(\mathrm{M}+1)^{+}$.

\section{3-Hydroxy-4-(3-nitrooxypropoxy)benzoic acid (28)}

To a solution of $27(0.56 \mathrm{~g}, 2.06 \mathrm{mmol})$ in THF $(10 \mathrm{~mL})$ and $\mathrm{H}_{2} \mathrm{O}(10 \mathrm{~mL})$, NaOH pellets (165 mg; $4.13 \mathrm{mmol}$ ) were added. The mixture was heated to $40{ }^{\circ} \mathrm{C}$ for $4 \mathrm{~h}$. The residue was treated with EtOAc $(10 \mathrm{~mL})$ and $\mathrm{H}_{2} \mathrm{O}(10 \mathrm{~mL})$. After separation, the aqueous layer was acidified with $\mathrm{HCl} 6 \mathrm{~N}$ and extracted twice with EtOAc $(20 \mathrm{~mL})$. The combined organic layers were dried with $\mathrm{MgSO}_{4}$, filtered, and concentrated under reduced pressure to give the title compound as a yellow solid; yield 59 \%. m.p. 166.5-169.5 ${ }^{\circ} \mathrm{C}$ (toluene). ${ }^{1} \mathrm{H}-\mathrm{NMR}$ (DMSO-d $)$ ) 2.14 (qi, 2H, - $\mathrm{OCH}_{2} \mathrm{CH}_{2}$ ), 4.12 (t, $\left.2 \mathrm{H},-\mathrm{OCH}_{2} \mathrm{CH}_{2-}\right), 4.74\left(\mathrm{t}, 2 \mathrm{H},-\mathrm{CH}_{2} \mathrm{ONO}_{2}\right), 7.00\left(\mathrm{~d}, 1 \mathrm{H}, \mathrm{C}_{6} \mathrm{H}_{3}\right), 7.35-7.42\left(\mathrm{~m}, 2 \mathrm{H}, \mathrm{C}_{6} \mathrm{H}_{3}\right), 9.27$ (svbr, 1H, OH), 12.58 (svbr, 1H, -COOH). ${ }^{13} \mathrm{C}-\mathrm{NMR}$ (DMSO-d 6 ) $\delta$ 26.0, 64.4, 70.8, 112.4, 116.1, 121.4, 123.4, 146.2, 150.4, 167.0. MS (CI) $m / z 258(\mathrm{M}+1)^{+}$.

\section{3-(Morpholin-4-ylmethyl)-4-[3-(nitrooxy)propoxy]benzoic acid (48)}

A solution of $29(0.56 \mathrm{mmol})$ in $\mathrm{MeOH}(5 \mathrm{~mL})$ and $1 \mathrm{~N} \mathrm{NaOH}(2 \mathrm{~mL})$ was stirred at room temperature for $4 \mathrm{~h}$. The solvent was then removed under reduced pressure, the residue dissolved in $\mathrm{H}_{2} \mathrm{O}(10 \mathrm{~mL})$, the $\mathrm{pH}$ adjusted to 7 , and the product extracted in continuous cycle for $18 \mathrm{~h}$ with EtOAc. The EtOAc layer was dried with $\mathrm{MgSO}_{4}$, filtered, and concentrated under reduced pressure 
to give the desired compound. Colourless oil; yield: 67\%. ${ }^{1} \mathrm{H}-\mathrm{NMR}\left(\mathrm{CDCl}_{3}\right) \delta 2.28$ (qi, 2H, $\left.\mathrm{OCH}_{2} \mathrm{CH}_{2-}\right), 2.79\left(\mathrm{~m}, 4 \mathrm{H},-\mathrm{CH}_{2} \mathrm{NCH}_{2}-\right), 3.77\left(\mathrm{~m}, 4 \mathrm{H},-\mathrm{CH}_{2} \mathrm{OCH}_{2}-\right), 3.85$ (s, 2H, - $\left.\mathrm{NCH}_{2} \mathrm{Ar}\right), 4.21(\mathrm{t}$, $\left.2 \mathrm{H},-\mathrm{OCH}_{2-}\right), 4.74\left(\mathrm{~m}, 2 \mathrm{H},-\mathrm{CH}_{2} \mathrm{ONO}_{2}\right), 7.07$ (d, 1H, $\left.\mathrm{C}_{6} \mathrm{H}_{3}\right), 7.98\left(\mathrm{~d}, 1 \mathrm{H}, \mathrm{C}_{6} \mathrm{H}_{3}\right), 8.04\left(\mathrm{~s}, 1 \mathrm{H}, \mathrm{C}_{6} \mathrm{H}_{3}\right)$. ${ }^{13} \mathrm{C}-\mathrm{NMR}\left(\mathrm{CDCl}_{3}\right) \delta 28.0,54.2,57.1,66.1,66.9,71.9,112.2,123.7,126.4,133.0,134.7,161.8$, 171.0 .

\section{General procedure for the preparation of aspirin esters $(30-37,49)$}

To a solution of $29(0.58 \mathrm{~g}, 2.52 \mathrm{mmol})$ in DMF $(8 \mathrm{~mL})$ the appropriate carboxylic acid derivative $(2.52 \mathrm{mmol})$ and $\mathrm{Cs}_{2} \mathrm{CO}_{3}(0.41 \mathrm{~g}, 1.26 \mathrm{mmol})$ were added. The mixture was stirred at room temperature for 24 hours, then poured into $\mathrm{H}_{2} \mathrm{O}(30 \mathrm{~mL})$ and extracted with EtOAc $(3 \times 5 \mathrm{~mL})$. The combined organic layers were dried with $\mathrm{MgSO}_{4}$, filtered, and concentrated under reduced pressure. The crude product thus obtained was purified by flash chromatography. Chromatographic eluents and yields of the products were as follows.

\{[2-(Acetyloxy)benzoyl]oxy\}methyl $\quad 3-(\{3-[$ tert-butoxycarbonyl)amino]propanoyl $\}$ oxy-4-[3(nitrooxy)propoxy]benzoate (30)

Eluent: PE/EtOAc 90/10 to 70/30 v/v; colourless oil; yield: $70 \% .{ }^{1} \mathrm{H}-\mathrm{NMR}\left(\mathrm{CDCl}_{3}\right) \delta 1.45(\mathrm{~s}, 9 \mathrm{H}$, $t$ - $\mathrm{Bu}$ ), 2.23 (qi, 2H, $-\mathrm{OCH}_{2} \mathrm{CH}_{2-}$ ), 2.35 (s, 3H, $\mathrm{CH}_{3} \mathrm{CO}$ ), 2.82 (t, 2H, $-\mathrm{CH}_{2} \mathrm{CH}_{2} \mathrm{NH}-$ ), 3.49-3.55 (m, $\left.2 \mathrm{H},-\mathrm{CH}_{2} \mathrm{CH}_{2} \mathrm{NH}-\right), 4.18$ (t, 2H, $-\mathrm{OCH}_{2} \mathrm{CH}_{2}$ ), 4.60 (t, 2H, $-\mathrm{CH}_{2} \mathrm{ONO}_{2}$ ), $5.06(\mathrm{~m}, 1 \mathrm{H},-\mathrm{NH}), 6.16$ (s, $\left.2 \mathrm{H},-\mathrm{OCH}_{2} \mathrm{O}-\right), 6.99$ (d, $\left.1 \mathrm{H}, \mathrm{C}_{6} \mathrm{H}_{3}\right), 7.11\left(\mathrm{~d}, 1 \mathrm{H}, \mathrm{C}_{6} \mathrm{H}_{4}\right), 7.33$ (t, 1H, $\left.\mathrm{C}_{6} \mathrm{H}_{4}\right), 7.60\left(\mathrm{t}, 1 \mathrm{H}, \mathrm{C}_{6} \mathrm{H}_{4}\right), 7.79-$ $7.80\left(\mathrm{~m}, 1 \mathrm{H}, \mathrm{C}_{6} \mathrm{H}_{3}\right), 7.98-8.01\left(\mathrm{~m}, 1 \mathrm{H}, \mathrm{C}_{6} \mathrm{H}_{3}\right), 8.07-8.10\left(\mathrm{~m}, 1 \mathrm{H}, \mathrm{C}_{6} \mathrm{H}_{4}\right) .{ }^{13} \mathrm{C}-\mathrm{NMR}\left(\mathrm{CDCl}_{3}\right) \delta 21.0$, 26.8, 28.4, 34.5, 36.0, 64.7, 69.4, 79.6, 79.8, 112.4, 121.9, 122.0, 124.0, 124.9, 126.2, 129.9, 132.3, 134.7, 139.2, 151.1, 154.3, 155.7, 163.1, 164.0, 169.7, 171.2. MS (CI) m/z $621(\mathrm{M}+1)^{+}$.

\{[2-(Acetyloxy)benzoyl]oxy\}methyl-3-(\{3-[tert-butoxycarbonyl)amino]propanoyl\}oxy-4-[3(nitrooxy)butoxy]benzoate (31)

Eluent: PE/EtOAc 90/10 to 70/30 v/v; colourless oil; yield: $45 \% .{ }^{1} \mathrm{H}-\mathrm{NMR}\left(\mathrm{CDCl}_{3}\right) \delta 1.45(\mathrm{~s}, 9 \mathrm{H}$, $t$-Bu), 1.82-2.03 (m, 4H, - $\mathrm{OCH}_{2} \mathrm{CH}_{2} \mathrm{CH}_{2-}$ ), 2.35 (s, 3H, $\left.\mathrm{CH}_{3} \mathrm{CO}-\right), 2.81$ (t, 2H, $\left.-\mathrm{CH}_{2} \mathrm{CH}_{2} \mathrm{NH}-\right), 3.52$ (q, $\left.2 \mathrm{H},-\mathrm{CH}_{2} \mathrm{CH}_{2} \mathrm{NH}-\right), 4.11\left(\mathrm{t}, 2 \mathrm{H},-\mathrm{OCH}_{2} \mathrm{CH}_{2}-\right), 4.51$ (t, $\left.2 \mathrm{H},-\mathrm{CH}_{2} \mathrm{ONO}_{2}\right), 5.05-5.15(\mathrm{~m}, 1 \mathrm{H}, \mathrm{NH})$, $6.16\left(\mathrm{~s}, 2 \mathrm{H},-\mathrm{OCH}_{2} \mathrm{O}-\right), 6.98\left(\mathrm{~d}, 1 \mathrm{H}, \mathrm{C}_{6} \mathrm{H}_{3}\right), 7.11\left(\mathrm{~d}, 1 \mathrm{H}, \mathrm{C}_{6} \mathrm{H}_{4}\right), 7.32\left(\mathrm{t}, 1 \mathrm{H}, \mathrm{C}_{6} \mathrm{H}_{4}\right), 7.60(\mathrm{t}, 1 \mathrm{H}$, $\left.\mathrm{C}_{6} \mathrm{H}_{4}\right)$, 7.79-7.80 (m, 1H, $\left.\mathrm{C}_{6} \mathrm{H}_{3}\right)$ 7.97-8.00 (m, $\left.1 \mathrm{H}, \mathrm{C}_{6} \mathrm{H}_{3}\right), 8.07-8.10\left(\mathrm{~m}, 1 \mathrm{H}, \mathrm{C}_{6} \mathrm{H}_{4}\right) .{ }^{13} \mathrm{C}-\mathrm{NMR}$ $\left(\mathrm{CDCl}_{3}\right) \delta 21.0,23.6,25.2,28.4,34.5,36.1,67.9,72.5,79.8,112.3,121.6,122.0,124.0,124.8$, $126.2,129.9,132.2,134.7,139.3,151.1,154.6,162.5,163.1,164.1,169.7 . \mathrm{MS}(\mathrm{CI}) \mathrm{m} / z 635$ $(\mathrm{M}+1)^{+}$.

$\{[2-($ Acetyloxy)benzoyl]oxy\}methyl-3-(\{3-[tert-butoxycarbonyl)amino]acetoxy $\}-4-[3-$ (nitrooxy)propoxy]benzoate (32) 
Eluent: PE/EtOAc 80/20 to 60/40 v/v; colourless oil; yield: $70 \% .{ }^{1} \mathrm{H}-\mathrm{NMR}\left(\mathrm{CDCl}_{3}\right) \delta 1.46(\mathrm{~s}, 9 \mathrm{H}$, $t$-Bu), 2.23 (qi, $2 \mathrm{H},-\mathrm{OCH}_{2} \mathrm{CH}_{2}$ ), 2.35 (s, 3H, $\mathrm{CH}_{3} \mathrm{CO}-$ ), 4.11-4.20 (m, 4H, $-\mathrm{CH}_{2} \mathrm{NH}-+-\mathrm{OCH}_{2} \mathrm{CH}_{2-}$ ), $4.63\left(\mathrm{t}, 2 \mathrm{H},-\mathrm{CH}_{2} \mathrm{ONO}_{2}\right), 5.06(\mathrm{sbr}, 1 \mathrm{H}, \mathrm{NH}), 6.16\left(\mathrm{~s}, 2 \mathrm{H},-\mathrm{OCH}_{2} \mathrm{O}-\right), 6.98\left(\mathrm{~d}, 1 \mathrm{H}, \mathrm{C}_{6} \mathrm{H}_{3}\right), 7.11(\mathrm{~d}$, $\left.1 \mathrm{H}, \mathrm{C}_{6} \mathrm{H}_{4}\right), 7.32\left(\mathrm{t}, 1 \mathrm{H}, \mathrm{C}_{6} \mathrm{H}_{4}\right), 7.60\left(\mathrm{t}, 1 \mathrm{H}, \mathrm{C}_{6} \mathrm{H}_{4}\right), 7.80\left(\mathrm{~m}, 1 \mathrm{H}, \mathrm{C}_{6} \mathrm{H}_{3}\right), 7.98-8.01\left(\mathrm{~m}, 1 \mathrm{H}, \mathrm{C}_{6} \mathrm{H}_{3}\right)$, 8.07-8.09 (m, 1H, $\left.\mathrm{C}_{6} \mathrm{H}_{4}\right) .{ }^{13} \mathrm{C}-\mathrm{NMR}\left(\mathrm{CDCl}_{3}\right) \delta 21.0,26.9,28.3,42.1,64.6,69.7,76.6,79.8,85.4$, $112.4,121.9,124.0,124.7,126.1,130.0,132.3,134.6,139.1,151.1,154.4,155.7,163.1,164.0$, 168.3, 169.7, 189.8. MS (CI) m/z $607(\mathrm{M}+1)^{+}$.

$\{[2-($ Acetyloxy $)$ benzoyl $]$ oxy $\}$ methyl-3-(\{3-[tert-butoxycarbonyl)amino]butanoyl $\}$ oxy-4-[3(nitrooxy)propoxy]benzoate (33)

Eluent: PE/EtOAc 80/20 to 60/40 v/v; colourless oil; yield: $72 \% .{ }^{1} \mathrm{H}-\mathrm{NMR}\left(\mathrm{CDCl}_{3}\right) \delta 1.45(\mathrm{~s}, 9 \mathrm{H}$, $t$-Bu), 1.93 (qi, 2H, - $\mathrm{CH}_{2} \mathrm{CH}_{2} \mathrm{NH}$ ), 2.25 (qi, 2H, - $\mathrm{OCH}_{2} \mathrm{CH}_{2}$ ), 2.35 (s, 3H, $\mathrm{CH}_{3} \mathrm{CO}$ ) ), 2.64 (t, 2H, $\mathrm{COCH}_{2} \mathrm{CH}_{2-}$ ), 3.22-3.28 (m, $\left.2 \mathrm{H},-\mathrm{CH}_{2} \mathrm{CH}_{2} \mathrm{NH}-\right), 3.56$ (sbr, $\left.1 \mathrm{H}, \mathrm{NH}\right), 4.17$ (t, $\left.2 \mathrm{H},-\mathrm{OCH}_{2} \mathrm{CH}_{2}-\right), 4.60$ (t, 2H, $-\mathrm{CH}_{2} \mathrm{ONO}_{2}$ ), 6.16 (s, 2H, - $\left.\mathrm{OCH}_{2} \mathrm{O}-\right), 6.98\left(\mathrm{~d}, 1 \mathrm{H}, \mathrm{C}_{6} \mathrm{H}_{3}\right), 7.11\left(\mathrm{~d}, 1 \mathrm{H}, \mathrm{C}_{6} \mathrm{H}_{4}\right), 7.32(\mathrm{t}, 1 \mathrm{H}$, $\left.\mathrm{C}_{6} \mathrm{H}_{4}\right)$, 7.57-7.62 (m, $\left.1 \mathrm{H}, \mathrm{C}_{6} \mathrm{H}_{4}\right)$, 7.77-7.78 (m, $\left.1 \mathrm{H}, \mathrm{C}_{6} \mathrm{H}_{3}\right), 7.96-8.00\left(\mathrm{~m}, 1 \mathrm{H}, \mathrm{C}_{6} \mathrm{H}_{3}\right)$, 8.06-8.10 (m, $\left.1 \mathrm{H}, \mathrm{C}_{6} \mathrm{H}_{4}\right) .{ }^{13} \mathrm{C}-\mathrm{NMR}\left(\mathrm{CDCl}_{3}\right) \delta 21.0,25.4,26.8,28.4,31.1,39.8,64.7,69.5,79.4,79.9,112.4$, $122.0,122.1,124.0,125.0,126.1,129.8,132.2$, 134.7, 139.5, 151.1, 154.5, 156.0, 163.1, 164.1, 169.7, 170.8. MS (CI) $m / z, 635(\mathrm{M}+1)^{+}$.

$\{[2-($ Acetyloxy)benzoyl]oxy\}methyl-3-(\{2-[tert-butoxycarbonyl)amino]propanoyl $\}$ oxy-4-[3(nitrooxy)propoxy]benzoate (34)

Eluent: PE/EtOAc 80/20 to 70/30 v/v; colourless oil; yield: $50 \%$. ${ }^{1} \mathrm{H}-\mathrm{NMR}\left(\mathrm{CDCl}_{3}\right) \delta 1.41-1.43$ (s, 19H, t-Bu), 1.57 (d, 3H, - $\mathrm{CHCH}_{3}$ ), 2.21 (qi, 2H, - $\mathrm{OCH}_{2} \mathrm{CH}_{2}$ ) , 2.35 (s, 3H, CH $\mathrm{CH}_{3}$ ), 4.16 (t, 2H, $\left.\mathrm{OCH}_{2} \mathrm{CH}_{2}-\right), 4.60-4.64\left(\mathrm{~m}, 3 \mathrm{H},-\mathrm{CH}_{2} \mathrm{ONO}_{2}+-\mathrm{CHCH}_{3}\right), 5.03-5.07(\mathrm{~m}, 1 \mathrm{H}, \mathrm{NH}), 6.16(\mathrm{~s}, 2 \mathrm{H},-$ $\left.\mathrm{OCH}_{2} \mathrm{O}-\right), 6.98\left(\mathrm{~d}, 1 \mathrm{H}, \mathrm{C}_{6} \mathrm{H}_{3}\right), 7.11\left(\mathrm{~d}, 1 \mathrm{H}, \mathrm{C}_{6} \mathrm{H}_{4}\right), 7.32$ (t, 2H, $\left.\mathrm{C}_{6} \mathrm{H}_{4}\right), 7.59$ (t, 1H, $\left.\mathrm{C}_{6} \mathrm{H}_{4}\right), 7.79-7.80$ $\left(\mathrm{m}, 1 \mathrm{H}, \mathrm{C}_{6} \mathrm{H}_{3}\right), 7.98-8.01\left(\mathrm{~m}, 1 \mathrm{H}, \mathrm{C}_{6} \mathrm{H}_{3}\right), 8.07-8.10$ 7.79-7.80 (m, 1H, $\left.\mathrm{C}_{6} \mathrm{H}_{4}\right) .{ }^{13} \mathrm{C}-\mathrm{NMR}\left(\mathrm{CDCl}_{3}\right) \delta$ 18.6, 21.0, 26.7, 28.3, 64.6, 69.5, 79.8, 112.4, 121.9, 122.0, 124.0, 124.7, 126.1, 130.0, 132.3, 134.7, 139.2, 151.1, 154.4, 163.0, 164.0, 169.7, 171.2. MS (CI) $m / z 621(\mathrm{M}+1)^{+}$.

\section{$\{[2-($ Acetyloxy)benzoyl]oxy\}methyl-3-(\{3-[tert-butoxycarbonyl)amino](tert-butyl-}

\section{dimethylsyliloxy)butoxy)-4-(3-nitrooxypropoxy)benzoate (35)}

Eluent: PE/EtOAc 70/30 v/v; colourless oil; yield: $35 \% .{ }^{1} \mathrm{H}-\mathrm{NMR}\left(\mathrm{CDCl}_{3}\right) \delta 0.09\left(s, 3 \mathrm{H}, \mathrm{CH}_{3} \mathrm{Si}-\right)$, $0.10\left(s, 3 \mathrm{H}, \mathrm{CH}_{3} \mathrm{Si}-\right), 0.88(s, 9 \mathrm{H}, t \mathrm{BuSi}-), 1.32\left(d, 3 \mathrm{H},-\mathrm{CHCH}_{3}\right), 1.46(s, 9 \mathrm{H}, t \mathrm{BuO}-), 2.18(q i, 2 \mathrm{H}$, $-\mathrm{OCH}_{2} \mathrm{CH}_{2-}$ ), 2.32 ( $\left.s, 3 \mathrm{H}, \mathrm{CH}_{3} \mathrm{CO}-\right), 4.13\left(t, 2 \mathrm{H},-\mathrm{OCH}_{2} \mathrm{CH}_{2-}\right), 4.44-4.47$ ( $\left.m, 1 \mathrm{H},-\mathrm{CHNH}-\right), 4.60-$ $4.67\left(m, 3 \mathrm{H},-\mathrm{CH}_{2} \mathrm{ONO}_{2}+-\mathrm{CHOSi}-\right), 5.24(d, 1 \mathrm{H},-\mathrm{NH}-), 6.15\left(s, 2 \mathrm{H},-\mathrm{OCH}_{2} \mathrm{O}-\right), 6.97(d, 1 \mathrm{H}$, $\left.\mathrm{C}_{6} \mathrm{H}_{3}\right), 7.10\left(d, 1 \mathrm{H}, \mathrm{C}_{6} \mathrm{H}_{4}\right), 7.30\left(t, 1 \mathrm{H}, \mathrm{C}_{6} \mathrm{H}_{4}\right), 7.54-7.60\left(m, 1 \mathrm{H}, \mathrm{C}_{6} \mathrm{H}_{4}\right), 7.69-7.70\left(m, 1 \mathrm{H}, \mathrm{C}_{6} \mathrm{H}_{3}\right)$, 7.95-7.99 $\left(m, 1 \mathrm{H}, \mathrm{C}_{6} \mathrm{H}_{3}\right), 8.04-8.07\left(m, 1 \mathrm{H}, \mathrm{C}_{6} \mathrm{H}_{4}\right) .{ }^{13} \mathrm{C}-\mathrm{NMR}\left(\mathrm{CDCl}_{3}\right) \delta-4.9,-4.1,18.0,20.9,25.8$, 
26.9, 28.4, 59.7, 64.9, 68.8, 69.7, 80.1, 112.7, 122.0, 122.3, 124.1, 124.6, 126.1, 129.8, 132.2, $134.6,139.8,151.2,154.6,156.1,163.0,164.0,169.1,169.4$.

\section{\{[2-(Acetyloxy)benzoyl]oxy\}methyl-3-(\{3-[tert-butoxycarbonyl)amino]propanoyl\}oxy-4-}

\section{[2,3bis(nitrooxy)propoxy]benzoate (36)}

Eluent: PE/EtOAc 80/20 to 60/40 v/v; colourless oil; yield: $47 \% .{ }^{1} \mathrm{H}-\mathrm{NMR}\left(\mathrm{CDCl}_{3}\right) \delta 1.45(\mathrm{~s}, 9 \mathrm{H}$, $t$-Bu), 2.34 (s, 3H, CH $\mathrm{CH}_{3}$-), 2.82 (t, $2 \mathrm{H},-\mathrm{CH}_{2} \mathrm{CH}_{2} \mathrm{NH}-$ ), 3.50-3.53 (m, 2H, $-\mathrm{CH}_{2} \mathrm{CH}_{2} \mathrm{NH}-$ ), 4.30 (d, $2 \mathrm{H},-\mathrm{OCH}_{2} \mathrm{CH}-$ ), 4.65-4.86 (m, AMX-like system, 2H, - $\mathrm{CHCH}_{2} \mathrm{ONO}_{2}$ ), 5.09 (svbr, 1H, -NH), 5.59$.62\left(\mathrm{~m}, 1 \mathrm{H},-\mathrm{CHCH}_{2} \mathrm{ONO}_{2}\right), 6.16\left(\mathrm{~s}, 2 \mathrm{H},-\mathrm{OCH}_{2} \mathrm{O}-\right), 6.97\left(\mathrm{~d}, 1 \mathrm{H}, \mathrm{C}_{6} \mathrm{H}_{3}\right), 7.11\left(\mathrm{~d}, 1 \mathrm{H}, \mathrm{C}_{6} \mathrm{H}_{4}\right), 7.32(\mathrm{t}$, $\left.1 \mathrm{H}, \mathrm{C}_{6} \mathrm{H}_{4}\right), 7.59\left(\mathrm{t}, 1 \mathrm{H}, \mathrm{C}_{6} \mathrm{H}_{4}\right), 7.80-7.81\left(\mathrm{~m}, 1 \mathrm{H}, \mathrm{C}_{6} \mathrm{H}_{3}\right), 7.96-8.00\left(\mathrm{~m}, 1 \mathrm{H}, \mathrm{C}_{6} \mathrm{H}_{3}\right), 8.07(\mathrm{~d}, 1 \mathrm{H}$, $\left.\mathrm{C}_{6} \mathrm{H}_{4}\right) .{ }^{13} \mathrm{C}-\mathrm{NMR}\left(\mathrm{CDCl}_{3}\right) \delta$ 21.0, 28.3, 31.2, 34.4, 65.6, 68.5, 76.1, 79.6, 79.9, 110.7, 121.9, 123.1, 124.0, 125.2, 126.2, 129.8, 132.2, 134.8, 139.4, 151.1, 153.4, 155.8, 163.1, 163.8, 169.7, 170.0. MS (CI) $m / z 682(\mathrm{M}+1)^{+}$.

\section{\{[2-(Acetyloxy)benzoyl]oxy\}methyl- 3-hydroxy-4-(3-nitrooxypropoxy)benzoate (37)}

Eluent: PE/EtOAc 90/10 to 70/30 v/v; white solid; yield: 37 \%. m.p.: 84.5-85.5 ${ }^{\circ} \mathrm{C}$. ${ }^{1} \mathrm{H}-\mathrm{NMR}$ $\left(\mathrm{CDCl}_{3}\right) \delta 2.26$ (qi, 2H, - $\left.\mathrm{OCH}_{2} \mathrm{CH}_{2}-\right), 2.35$ (s, 3H, $\mathrm{CH}_{3} \mathrm{CO}$ ) $), 4.22$ (t, 2H, $\mathrm{OCH}_{2} \mathrm{CH}_{2^{-}}$), 4.65 (t, 2H, $\mathrm{CH}_{2} \mathrm{ONO}_{2}$ ), 5.62 (s, $\left.1 \mathrm{H}, \mathrm{OH}\right), 6.16$ (s, 2H, $\left.-\mathrm{OCH}_{2} \mathrm{O}-\right), 6.85$ (d, $\left.1 \mathrm{H}, \mathrm{C}_{6} \mathrm{H}_{3}\right), 7.12\left(\mathrm{~d}, 1 \mathrm{H}, \mathrm{C}_{6} \mathrm{H}_{4}\right), 7.32$ $\left(\mathrm{t}, 1 \mathrm{H}, \mathrm{C}_{6} \mathrm{H}_{4}\right), 7.56-7.67\left(\mathrm{~m}, 3 \mathrm{H}, \mathrm{C}_{6} \mathrm{H}_{3}+\mathrm{C}_{6} \mathrm{H}_{4}\right), 8.07-8.10\left(\mathrm{~m}, 1 \mathrm{H}, \mathrm{C}_{6} \mathrm{H}_{4}\right) .{ }^{13} \mathrm{C}-\mathrm{NMR}\left(\mathrm{CDCl}_{3}\right) \delta 21.0$, 26.9, 65.1, 69.6, 79.8, 110.8, 116.5, 122.1, 122.5, 123.5, 124.0, 126.1, 132.3, 134.6, 145.4, 149.8, 151.0, 163.1, 164.7, 169.8. MS (CI) m/z $450(\mathrm{M}+1)^{+}$.

\section{$\{[2-($ Acetyloxy)benzoyl]oxy\}methyl}

\section{3-(morpholin-4-ylmethyl)-4-[3-}

\section{(nitrooxy)propoxy]benzoate oxalate (49)}

The crude product was purified by flash chromatography (PE/EtOAc 60/40 v/v) to give $\{[2-$ (acetyloxy)benzoyl]oxy\} methyl 4-(morpholin-4-ylmethyl)-3-[3-(nitrooxy)propoxy]benzoate (0.38 g) as a colourless oil. To a solution of $\{[2$-(acetyloxy)benzoyl]oxy\}methyl 4-(morpholin-4ylmethyl)-3-[3-(nitrooxy)propoxy]benzoate in EtOAc $(3 \mathrm{~mL})$ was added a solution of $\mathrm{H}_{2} \mathrm{C}_{2} \mathrm{O}_{4}(0.06$ $\mathrm{g}, 1 \mathrm{eq})$ in EtOAc $(2 \mathrm{~mL})$ and the title compound $(0.17 \mathrm{~g})$ was obtained by filtration as a white solid; yield: $20 \%$. m.p. $135-139{ }^{\circ} \mathrm{C}$ (dec.). ${ }^{1} \mathrm{H}-\mathrm{NMR}\left(\mathrm{DMSO}_{-} \mathrm{d}_{6}\right) \delta$ 2.17-2.25 (m, 5H, - $\mathrm{OCH}_{2} \mathrm{CH}_{2^{-}}+$ $\left.-\mathrm{COCH}_{3}\right), 2.71\left(\mathrm{~m}, 4 \mathrm{H},-\mathrm{CH}_{2} \mathrm{NCH}_{2-}\right), 3.64\left(\mathrm{~m}, 4 \mathrm{H},-\mathrm{CH}_{2} \mathrm{OCH}_{2^{-}}\right), 3.83\left(\mathrm{~s}, 2 \mathrm{H},-\mathrm{NCH}_{2} \mathrm{Ar}\right), 4.20(\mathrm{t}$, $\left.2 \mathrm{H},-\mathrm{OCH}_{2}-\right), 4.74\left(\mathrm{t}, 2 \mathrm{H},-\mathrm{CH}_{2} \mathrm{ONO}_{2}\right), 6.14$ (s, 2H, $\left.-\mathrm{OCH}_{2} \mathrm{O}-\right), 7.19$ (d, 1H, Arom), $7.27(\mathrm{~d}, 1 \mathrm{H}$, Arom), 7.42 (t, 1H, Arom), 7.73 (t, 1H, Arom), 7.96-8.05 (m, 3H, Arom), 8.06 (s, 1H, Arom). ${ }^{13} \mathrm{C}-$ NMR (DMSO-d 6 ) $\delta$ 20.9, 26.3, 52.7, 54.9, 65.2, 65.3, 71.3, 80.5, 112.2, 120.5, 122.2, 124.5, 126.7, $131.8,132.1,133.2,135.4,150.5,161.6,162.6,163.1,164.3,169.3$.

General procedure for the preparation of aminoacid derivatives (38-44) 
A solution of the appropriate BOC-protected intermediate $(2.00 \mathrm{mmol})$ in dry dioxane $\mathrm{HCl} 2.36 \mathrm{M}$ (12.6 mL, $29.0 \mathrm{mmol})$, was stirred under inert atmosphere for $3 \mathrm{~h}$. The mixture was concentrated under reduced pressure.

Hydrochloridric salt of $\{[2-(\operatorname{acetyloxy})$ benzoyl]oxy $\}$ methyl-3-[(3-[aminopropanoyl)oxy]-4-[3(nitrooxy)propoxy]benzoate (38)

The crude product was tritured with dry $\mathrm{Et}_{2} \mathrm{O}$ to give the title compound as a white solid; yield: 89 \%. m.p.: 94.5-95.5 ${ }^{\circ} \mathrm{C} .{ }^{1} \mathrm{H}-\mathrm{NMR}$ (DMSO-d 6 ) $\delta 2.16$ (qi, 2H, - $\mathrm{OCH}_{2} \mathrm{CH}_{2^{-}}$), 2.25 (s, 3H, CH $\mathrm{DH}_{3}$ ), 3.01-3.06 (m, 2H, $\left.-\mathrm{CH}_{2} \mathrm{CH}_{2} \mathrm{NH}_{2}\right), 3.11-3.13\left(\mathrm{~m}, 2 \mathrm{H},-\mathrm{CH}_{2} \mathrm{CH}_{2} \mathrm{NH}_{2}\right), 4.21\left(\mathrm{t}, 2 \mathrm{H},-\mathrm{OCH}_{2} \mathrm{CH}_{2}-\right), 4,63$ (t, 2H, $-\mathrm{CH}_{2} \mathrm{ONO}_{2}$ ), 6.14 (s, 2H, $\left.-\mathrm{OCH}_{2} \mathrm{O}-\right)$, 7.26-7.34 (m, 2H, $\left.\mathrm{C}_{6} \mathrm{H}_{3}+\mathrm{C}_{6} \mathrm{H}_{4}\right), 7.44\left(\mathrm{t}, 1 \mathrm{H}, \mathrm{C}_{6} \mathrm{H}_{4}\right)$, 7.71-7.77 (m, $\left.1 \mathrm{H}, \mathrm{C}_{6} \mathrm{H}_{4}\right), 7.82-7.83\left(\mathrm{~m}, 1 \mathrm{H}, \mathrm{C}_{6} \mathrm{H}_{3}\right), 7.93-8.00\left(\mathrm{~m}, 2 \mathrm{H}, \mathrm{C}_{6} \mathrm{H}_{3}+\mathrm{C}_{6} \mathrm{H}_{4}\right), 8.22$ (svvbr, $\left.2 \mathrm{H},-\mathrm{NH}_{2}\right) .{ }^{13} \mathrm{C}-\mathrm{NMR}\left(\mathrm{CDCl}_{3}\right) \delta 21.0,26.6,31.0,35.5,65.0,70.1,80.0,112.4,121.7,122.0,124.0$, $124.8,126.2,129.9,132.3,134.7,139.1,151.0,154.4,163.1,164.1,169.0,169.7$.

Hydrochloridric salt of $\{[2-(\operatorname{acetyloxy})$ benzoyl]oxy\}methyl-3-[(3-[aminopropanoyl)oxy]-4-[3(nitrooxy)butoxy]benzoate (39)

The crude product was purified by flash chromatography $\left(\mathrm{H}_{2} \mathrm{O} / \mathrm{CH}_{3} \mathrm{CN} / \mathrm{HCl} 60 / 40 / 0.1 \mathrm{v} / \mathrm{v} / \mathrm{v}\right)$ to give the title compound as a colourless oil; yield: $50 \% .{ }^{1} \mathrm{H}-\mathrm{NMR}\left(\mathrm{DMSO}-\mathrm{d}_{6}+\mathrm{CDCl}_{3}\right) \delta 1.78-1.94$ (m, 4H, - $\mathrm{OCH}_{2} \mathrm{CH}_{2} \mathrm{CH}_{2-}$ ), 2.28 (s, 3H, $\left.\mathrm{CH}_{3} \mathrm{CO}-\right), 3.09$ (t, $\left.2 \mathrm{H},-\mathrm{CH}_{2} \mathrm{CH}_{2} \mathrm{NH}-\right), 3.21$ (t, 2H, $\left.\mathrm{CH}_{2} \mathrm{CH}_{2} \mathrm{NH}-\right), 4.13$ (t, $\left.2 \mathrm{H},-\mathrm{OCH}_{2} \mathrm{CH}_{2}-\right), 4.58$ (t, 2H, $-\mathrm{CH}_{2} \mathrm{ONO}_{2}$ ), 6.14 (s, 2H, -OCH $\left.\mathrm{O}-\right), 7.17-$ $7.21\left(\mathrm{~m}, 2 \mathrm{H}, \mathrm{C}_{6} \mathrm{H}_{3}+\mathrm{C}_{6} \mathrm{H}_{4}\right), 7.42\left(\mathrm{t}, 1 \mathrm{H}, \mathrm{C}_{6} \mathrm{H}_{4}\right), 7.81\left(\mathrm{t}, 1 \mathrm{H}, \mathrm{C}_{6} \mathrm{H}_{4}\right), 7.79-7.80\left(\mathrm{~m}, 1 \mathrm{H}, \mathrm{C}_{6} \mathrm{H}_{3}\right), 7.94-$ $8.03\left(\mathrm{~m}, 2 \mathrm{H}, \mathrm{C}_{6} \mathrm{H}_{3}+\mathrm{C}_{6} \mathrm{H}_{4}\right), 8.34$ (svvbr, $\left.2 \mathrm{H}, \mathrm{NH}_{2}\right) .{ }^{13} \mathrm{C}-\mathrm{NMR}\left(\mathrm{DMSO}-\mathrm{d}_{6}+\mathrm{CDCl}_{3}\right) \delta 21.4,23.8$, $25.5,31.9,35.4,68.7,73.8,80.6,113.7,121.4,122.7,124.7,125.0,126.9,130.3,132.3,135.5$, $139.6,151.2,155.4,163.5,164.3,169.0,169.7$.

Hydrochloridric salt of $\quad\{[2-(\operatorname{acetyloxy}) b e n z o y l] 0 x y\}$ methyl-3-[(2-amino)acetoxy]-4-[3(nitrooxy)propoxy]benzoate (40)

The crude product was tritured with dry $\mathrm{Et}_{2} \mathrm{O}$ to give the title compound as a white solid; yield: 40 \%. m.p.: 60.5-62.5 ${ }^{\circ} \mathrm{C} .{ }^{1} \mathrm{H}-\mathrm{NMR}\left(\mathrm{CDCl}_{3}\right) \delta 2.16\left(\mathrm{~m}, 2 \mathrm{H},-\mathrm{OCH}_{2} \mathrm{CH}_{2}\right.$ ) $), 2.31$ (s, 3H, CH $\left.3 \mathrm{CO}-\right), 3.99$ $(\mathrm{m}, 2 \mathrm{H}),, 4.20(\mathrm{t}, 2 \mathrm{H})\left(-\mathrm{CH}_{2} \mathrm{NH}_{2}+\mathrm{OCH}_{2} \mathrm{CH}_{2}-\right), 4.53\left(\mathrm{t}, 2 \mathrm{H},-\mathrm{CH}_{2} \mathrm{ONO}_{2}\right), 6.16\left(\mathrm{~s}, 2 \mathrm{H},-\mathrm{OCH} \mathrm{O}_{2}\right)$, $6.83\left(\mathrm{~d}, 1 \mathrm{H}, \mathrm{C}_{6} \mathrm{H}_{3}\right), 7.08\left(\mathrm{~d}, 1 \mathrm{H}, \mathrm{C}_{6} \mathrm{H}_{4}\right), 7.27\left(\mathrm{t}, 1 \mathrm{H}, \mathrm{C}_{6} \mathrm{H}_{4}\right), 7.55\left(\mathrm{t}, 1 \mathrm{H}, \mathrm{C}_{6} \mathrm{H}_{4}\right), 7.71\left(\mathrm{~s}, 1 \mathrm{H}, \mathrm{C}_{6} \mathrm{H}_{3}\right)$, $7.86\left(\mathrm{~d}, 1 \mathrm{H}, \mathrm{C}_{6} \mathrm{H}_{3}\right), 8.03\left(\mathrm{~d}, 1 \mathrm{H}, \mathrm{C}_{6} \mathrm{H}_{4}\right), 8.69$ (svvbr, 3H, $\left.\mathrm{NH}_{3}{ }^{+}\right) .{ }^{13} \mathrm{C}-\mathrm{NMR}\left(\mathrm{CDCl}_{3}\right) \delta 20.9,26.5$, $40.4,65.2,70.5,79.9,112.5,121.5,122.0,124.0,124.3,126.2$, 130.2, 132.2, 134.7, 138.5, 151.0, $154.2,158.4,163.0,163.9,165.7,169.7$.

Hydrochloridric salt of $\{[2-($ acetyloxy)benzoyl]oxy\}methyl-3-[(4-amino)butanoyl]oxy-4-[3(nitrooxy)propoxy]benzoate (41) 
The crude product was purified by flash chromatography $\left(\mathrm{H}_{2} \mathrm{O} / \mathrm{CH}_{3} \mathrm{CN} / \mathrm{HCl} 70 / 30 / 0.1 \mathrm{v} / \mathrm{v} / \mathrm{v}\right)$ to give the title compound as a colourless oil; yield: $42 \% .{ }^{1} \mathrm{H}-\mathrm{NMR}\left(\mathrm{CDCl}_{3}\right) \delta 2.14-2.18(\mathrm{~m}, 4 \mathrm{H}$, $\mathrm{OCH}_{2} \mathrm{CH}_{2-}+-\mathrm{CH}_{2} \mathrm{CH}_{2} \mathrm{NH}_{2}$ ), 2.32 (s, 3H, $\mathrm{CH}_{3} \mathrm{CO}-$ ), 2.74 (t, 2H, $\mathrm{COCH}_{2} \mathrm{CH}_{2-}$ ), 3.10-3.20 (m, 2H, $\left.\mathrm{CH}_{2} \mathrm{CH}_{2} \mathrm{NH}_{2}\right), 4.07$ (t, 2H, $\left.-\mathrm{OCH}_{2} \mathrm{CH}_{2}-\right), 4.56$ (t, 2H, $\left.-\mathrm{CH}_{2} \mathrm{ONO}_{2}\right), 6.12\left(\mathrm{~s}, 2 \mathrm{H},-\mathrm{OCH}_{2} \mathrm{O}-\right), 6.90$ (d, $\left.1 \mathrm{H}, \mathrm{C}_{6} \mathrm{H}_{3}\right), 7.09\left(\mathrm{~d}, 1 \mathrm{H}, \mathrm{C}_{6} \mathrm{H}_{4}\right), 7.29\left(\mathrm{t}, 1 \mathrm{H}, \mathrm{C}_{6} \mathrm{H}_{4}\right), 7.56\left(\mathrm{t}, 1 \mathrm{H}, \mathrm{C}_{6} \mathrm{H}_{4}\right), 7.75-7.76\left(\mathrm{~m}, 1 \mathrm{H}, \mathrm{C}_{6} \mathrm{H}_{3}\right)$, 7.90-7.94 (m, $\left.1 \mathrm{H}, \mathrm{C}_{6} \mathrm{H}_{3}\right), 8.02-8.06\left(\mathrm{~m}, 1 \mathrm{H}, \mathrm{C}_{6} \mathrm{H}_{4}\right), 8.30$ (svvbr, $\left.3 \mathrm{H}, \mathrm{NH}_{3}{ }^{+}\right) .{ }^{13} \mathrm{C}-\mathrm{NMR}\left(\mathrm{CDCl}_{3}\right) \delta$ 21.0, 22.6, 26.7, 30.6, 39.2, 65.0, 70.0, 79.9, 112.4, 121.7, 122.0, 124.0, 124.8, 126.2, 129.8, 132.2, 134.7, 139.4, 151.0, 154.5, 163.1, 164.1. 169.7, 170.4 .

Hydrochloridric salt of $\{[2$-(acetyloxy)benzoyl]oxy\}methyl-3-[(2-amino)propanoyl]oxy-4-[3(nitrooxy)propoxy]benzoate (42)

The crude product was purified by flash chromatography $\left(\mathrm{H}_{2} \mathrm{O} / \mathrm{CH}_{3} \mathrm{CN} / \mathrm{HCl} 80 / 20 / 0.1 \mathrm{v} / \mathrm{v} / \mathrm{v}\right.$ to 60/40/0.1 v/v/v) to give the title compound as a white solid; yield: $44 \%$. m.p.: 65.5-69.0 ${ }^{\circ} \mathrm{C}$. ${ }^{1} \mathrm{H}$ $\mathrm{NMR}\left(\mathrm{CDCl}_{3}\right) \delta 1.78\left(\mathrm{~d}, 3 \mathrm{H},-\mathrm{CHCH}_{3}\right), 2.09-2.11\left(\mathrm{~m}, 2 \mathrm{H},-\mathrm{OCH}_{2} \mathrm{CH}_{2}-\right), 2.32$ (s, 3H, CH $\left.\mathrm{CO}_{3}\right)$, $4.03\left(\mathrm{~m}, 2 \mathrm{H},-\mathrm{OCH}_{2} \mathrm{CH}_{2}-\right), 4.40\left(\mathrm{~m}, 1 \mathrm{H},-\mathrm{CHCH}_{3}\right), 4.53\left(\mathrm{t}, 2 \mathrm{H},-\mathrm{CH}_{2} \mathrm{ONO}_{2}\right), 6.12$ (s, $\left.2 \mathrm{H},-\mathrm{OCH}_{2} \mathrm{O}-\right), 6.84$ (d, 1H, $\left.\mathrm{C}_{6} \mathrm{H}_{3}\right), 7.10$ (d, 1H, $\left.\mathrm{C}_{6} \mathrm{H}_{4}\right), 7.29$ (t, 1H, $\left.\mathrm{C}_{6} \mathrm{H}_{4}\right), 7.65\left(\mathrm{t}, 1 \mathrm{H}, \mathrm{C}_{6} \mathrm{H}_{4}\right), 7.75$ $\left(\mathrm{s}, 1 \mathrm{H}, \mathrm{C}_{6} \mathrm{H}_{3}\right), 7.86\left(\mathrm{~d}, 1 \mathrm{H}, \mathrm{C}_{6} \mathrm{H}_{3}\right), 8.02\left(\mathrm{~d}, 1 \mathrm{H}, \mathrm{C}_{6} \mathrm{H}_{4}\right), 8.84\left(\mathrm{svvbr}, 3 \mathrm{H}, \mathrm{NH}_{3}{ }^{+}\right) .{ }^{13} \mathrm{C}-\mathrm{NMR}\left(\mathrm{CDCl}_{3}\right) \delta$ 16.1, 21.0, 26.6, 65.1, 70.1, 79.9, 112.4, 121.6, 122.0, 124.0, 124.4, 126.2, 130.3, 132.2, 134.7, $138.5,151.0,154.2,163.0,163.9,167.8,169.7$.

Hydrochloridric salt of $\{[2-($ acetyloxy)benzoyl $]$ oxy $\}$ methyl3-[2-amino-3-hydroxybutoxy]-4-(3nitrooxypropoxy)benzoate (43).

The crude product was tritured with dry $\mathrm{Et}_{2} \mathrm{O}$ to give the title compound as a white solid; yield: 70 \%. m.p.: 87.5-88.5 ${ }^{\circ} \mathrm{C} .{ }^{1} \mathrm{H}-\mathrm{NMR}\left(\mathrm{CDCl}_{3}\right) \delta 1.40\left(d, 3 \mathrm{H},-\mathrm{CHCH}_{3}\right), 2.08\left(m, 2 \mathrm{H},-\mathrm{OCH}_{2} \mathrm{CH}_{2-}\right), 2.24$ $\left(s, 3 \mathrm{H}, \mathrm{CH}_{3} \mathrm{CO}-\right), 3.95\left(t, 2 \mathrm{H},-\mathrm{OCH}_{2} \mathrm{CH}_{2-}\right), 4.26\left(m, 1 \mathrm{H},-\mathrm{CHCH}_{3}\right), 4.35(m, 1 \mathrm{H},-\mathrm{OH}), 4.44(t, 2 \mathrm{H}$, $\left.-\mathrm{CH}_{2} \mathrm{ONO}_{2}\right), 6.01\left(s, 2 \mathrm{H},-\mathrm{OCH}_{2} \mathrm{O}-\right), 6.90\left(d, 1 \mathrm{H}, \mathrm{C}_{6} \mathrm{H}_{3}\right), 7.00\left(d, 1 \mathrm{H}, \mathrm{C}_{6} \mathrm{H}_{4}\right), 7.22\left(t, 1 \mathrm{H}, \mathrm{C}_{6} \mathrm{H}_{4}\right)$, $7.47\left(t, 1 \mathrm{H}, \mathrm{C}_{6} \mathrm{H}_{4}\right), 7.73\left(s, 1 \mathrm{H}, \mathrm{C}_{6} \mathrm{H}_{3}\right), 7.82\left(d, 1 \mathrm{H}, \mathrm{C}_{6} \mathrm{H}_{3}\right), 7.95\left(d, 1 \mathrm{H}, \mathrm{C}_{6} \mathrm{H}_{4}\right), 8.83(s v v b r, 3 \mathrm{H}$, $\left.\mathrm{NH}_{3}{ }^{+}\right) .{ }^{13} \mathrm{C}-\mathrm{NMR}\left(\mathrm{CDCl}_{3}\right) \delta 13.2,19.5,19.9,25.5,64.1,65.2,69.1,79.0,120.5,120.9,122.9,125.2$, $129.3,131.1,133.7,137.4,150.0,153.2,162.0,162.2,162.9,165.1,168.7$.

Hydrochloridric salt of $\{[2-(\operatorname{acetyloxy})$ benzoyl $]$ oxy $\}$ methyl-3-[(3-[aminopropanoyl)oxy]-4-[2,3bis(nitrooxy)propoxy]benzoate (44)

The crude product was tritured with dry $\mathrm{Et}_{2} \mathrm{O}$ to give the title compound as a foam; yield: $79 \%$. ${ }^{1} \mathrm{H}$ NMR (DMSO-d 6 ) $\delta 2.26$ (s, 3H, $\mathrm{CH}_{3} \mathrm{CO}-$ ), 3.02-3.13 (m, 4H, - $\mathrm{CH}_{2} \mathrm{CH}_{2} \mathrm{NH}_{2}$ ), 4.46-4.62 (m, AMXlike system, 2H, - $\mathrm{OCH}_{2} \mathrm{CH}$-), 4.85-5.06 (m, AMX-like system, 2H, - $\mathrm{CHCH}_{2} \mathrm{ONO}_{2}$ ), 5.82-5.87 (m, $\left.1 \mathrm{H},-\mathrm{CHCH}_{2} \mathrm{ONO}_{2}\right), 6.15$ (s, 2H, $\left.-\mathrm{OCH}_{2} \mathrm{O}-\right), 7.28$ (d, $\left.1 \mathrm{H}, \mathrm{C}_{6} \mathrm{H}_{3}\right), 7.36-7.47\left(\mathrm{~m}, 2 \mathrm{H}, \mathrm{C}_{6} \mathrm{H}_{3}+\mathrm{C}_{6} \mathrm{H}_{4}\right)$, 7.71-7.74 (m, $\left.1 \mathrm{H}, \mathrm{C}_{6} \mathrm{H}_{4}\right), 7.76-7.77\left(\mathrm{~m}, 1 \mathrm{H}, \mathrm{C}_{6} \mathrm{H}_{3}\right), 7.95-8.00\left(\mathrm{~m}, 2 \mathrm{H}, \mathrm{C}_{6} \mathrm{H}_{3}+\mathrm{C}_{6} \mathrm{H}_{4}\right), 8.33$ (svvbr, 
$\left.2 \mathrm{H},-\mathrm{NH}{ }_{2}\right) .{ }^{13} \mathrm{C}-\mathrm{NMR}\left(\mathrm{CDCl}_{3}\right) \delta 20.6,31.0,34.3,66.2,69.7,77.4,80.3,113.8,121.5,121.9,124.2$,

$124.5,126.3,129.6,131.5,135.1,138.8,150.1,153.7,163.4,166.4,168.1,169.0$.

\section{Solubility study.}

The solubility of the compounds in water was determined at $25 \pm 1{ }^{\circ} \mathrm{C}$, adding excess amounts of the compounds to water in test tubes; the mixtures were sonicated for $10 \mathrm{~min}$ and kept under magnetic stirring for $30 \mathrm{~min}$. This time was chosen to minimize hydrolysis during the test. After filtration, an aliquot of the filtrate was diluted with an appropriate amount of water, and analysed by HPLC for the quantitation of the compounds, as reported in the stability study experimental section.

\section{Stability Studies}

Evaluation of stability in aqueous buffered solutions. A solution of each compound (10 $\mathrm{mM})$ in acetonitrile/water $(50 / 50, \mathrm{v} / \mathrm{v})$ was added to $\mathrm{HCl} 0.1 \mathrm{M}$ or to phosphate buffer $\mathrm{pH} 7.4(50 \mathrm{mM})$ preheated to $37{ }^{\circ} \mathrm{C}$; the final concentration of the compound was $100 \mu \mathrm{M}$. The resulting solution was maintained at $37 \pm 0.5{ }^{\circ} \mathrm{C}$ and, at appropriate time intervals, a $20 \mu \mathrm{L}$ aliquot of reaction solution was analyzed by RP-HPLC, as described below.

Evaluation of stability in human serum. A solution of each compound $(10 \mathrm{mM})$ in acetonitrile/water (50/50, v/v) was added to human serum (from human male AB plasma, Sigma) preheated to $37{ }^{\circ} \mathrm{C}$; the final concentration of the compound was $200 \mu \mathrm{M}$. The resulting solution was incubated at $37 \pm 0.5{ }^{\circ} \mathrm{C}$ and, at appropriate time intervals, $300 \mu \mathrm{L}$ of reaction mixture were withdrawn and added to $300 \mu \mathrm{L}$ of acetonitrile containing $0.1 \%$ trifluoroacetic acid, in order to deproteinize the serum. The sample was sonicated, vortexed and then centrifuged for $10 \mathrm{~min}$ at $2150 \mathrm{~g}$; the clear supernatant was filtered through $0.45 \mu \mathrm{m}$ PTFE filters (Alltech) and analyzed by RP-HPLC. The reverse-phase HPLC procedure separated and quantitated the remaining compound and the products of hydrolysis (ASA, SA, nirooxy-substituted carboxylic acid).

HPLC analyses were performed with a HP 1100 chromatograph system (Agilent Technologies, Palo Alto, CA, USA) equipped with a quaternary pump (model G1311A), a membrane degasser (G1379A), and a diode-array detector (DAD) (model G1315B) integrated into the HP1100 system. Data were analyzed by the HP ChemStation system (Agilent Technologies). The analytical column was a Nucleosil 100-5C18 Nautilus $(250 \times 4.6 \mathrm{~mm}, 5 \mu \mathrm{m}$ particle size) (Macherey-Nagel). The samples were analyzed using a gradient method, employing a mobile phase consisting of acetonitrile/water with $0.1 \%$ trifluoroacetic acid $40 / 60(\mathrm{v} / \mathrm{v})$ over the first $2 \mathrm{~min}$, grading to $60 / 40$ at $11 \mathrm{~min}$, keeping 60/40 until $16 \mathrm{~min}$, and then returning to 40/60 at $20 \mathrm{~min}$. The flow-rate was 1.2 $\mathrm{mL} / \mathrm{min}$. The injection volume was $20 \mu \mathrm{L}$ (Rheodyne, Cotati, CA). The column effluent was 
monitored at $226 \mathrm{~nm}$ (for all prodrugs and the majority of metabolites) and at $240 \mathrm{~nm}$ (for salicylic acid) referenced against a $600 \mathrm{~nm}$ wavelength. Quantitation was done using calibration curves of compounds and the relative metabolites, chromatographed under the same conditions; the linearity of the calibration curves was determined in a concentration range of $1-200 \mu \mathrm{M}\left(\mathrm{r}^{2}>0.99\right)$.

\section{Inhibition of human platelet aggregation in vitro}

Venous blood samples were obtained from healthy volunteers who had not taken any drug for at least two weeks. Volunteers, who were treated according to the Helsinki protocol for biomedical experimentation, gave their informed consent to the use of blood samples for research purposes. Platelet rich plasma (PRP) was prepared by centrifugation of citrated blood at $200 \mathrm{~g}$ for 20 minutes. Aliquots $(500 \mu \mathrm{L})$ of PRP were placed in aggregometer (Chrono-log 4902D) cuvettes and aggregation was recorded as increased light transmission under continuous stirring (1000 rpm) at 37 ${ }^{\circ} \mathrm{C}$ for 10 minutes after addition of the stimulus. Collagen at a submaximal concentration (0.8-1.5 $\mu \mathrm{gmL}^{-1}$ ) was used as platelet activator in PRP. The compounds under study were preincubated with PRP for 10 min before addition of the stimulus (collagen). Drug vehicle alone (0.5\% DMSO) added to PRP did not affect platelet function in control samples.

The antiaggregatory activity of the tested compounds is expressed as \% inhibition of platelet aggregation compared to control samples. For most of the active compounds, $\mathrm{IC}_{50}$ values could be calculated by non-linear regression analysis, otherwise $\%$ inhibition at maximal concentration tested $(300 \mu \mathrm{M})$ is reported.

\section{Vasodilator activity}

Thoracic aortas were isolated from male Wistar rats weighing 180-200 g. As few animals as possible were used. The purposes of the studies and the protocols used have been approved by the Ministry of Health, , Rome, Italy. The endothelium was removed and the vessels were helically cut: four to six strips were obtained from each aorta. The tissue was mounted under $1.0 \mathrm{~g}$ tension in organ baths containing $30 \mathrm{~mL}$ of Krebs-bicarbonate buffer, with the following composition (mM): $\mathrm{NaCl} 111.2, \mathrm{KCl} 5.0, \mathrm{CaCl}_{2} 2.5, \mathrm{MgSO}_{4}$ 1.2, $\mathrm{KH}_{2} \mathrm{PO}_{4}$ 1.0, $\mathrm{NaHCO}_{3}$ 12.0, glucose 11.1, maintained at $37{ }^{\circ} \mathrm{C}$ and gassed with $95 \% \mathrm{O}_{2}-5 \% \mathrm{CO}_{2}(\mathrm{pH}=7.4)$. The aortic strips were allowed to equilibrate for $120 \mathrm{~min}$ and then contracted with $1 \mu \mathrm{M}$ L-phenylephrine. When the response to the agonist reached a plateau, cumulative concentrations of the vasodilating agent were added. Results are expressed as $\mathrm{EC}_{50} \pm \mathrm{SE}(\mu \mathrm{M})$. The effects of $1 \mu \mathrm{M}$ ODQ on relaxation were evaluated in separate series of experiments, in which the conpound was added to the organ bath 5 minutes before contraction. Responses were recorded by an isometric transducer connected to the MacLab System PowerLab. Addition of drug vehicle (DMSO) had no appreciable effect on contraction. 


\section{Anti-inflammatory activity.}

Male Wistar rats, weighing 180-200 g (Harlan, S. Pietro al Natisone, Italy) were individually housed in hanging stainless-steel cages with grid floors, at constant room temperature $\left(25 \pm 1{ }^{\circ} \mathrm{C}\right)$ and humidity $(60 \pm 5 \%)$, with an artificial 12:12 h light/dark cycle. Acute edema was induced in conscious rats by intraplantar injection into the right hind paw of $0.1 \mathrm{ml}$ of $1 \%$ carrageenan, suspended in $1 \%$ carboxymethylcellulose (CMC). Immediately after carrageenan injection, compound or vehicle $(1 \% \mathrm{CMC})$ was administered intragastrically to different groups of rats in a volume of $10 \mathrm{mLkg}-1$. ASA was administered as reference drug at the dose of $120 \mathrm{mgkg}-1$ and the two selected NO-donor ASA pro-drugs, 38 and 49, were administered at a dose equimolar to 120 mgkg-1 ASA. Groups of 6 animals were used. Paw volume was measured with a water plethysmometer (Basile, Comerio, Italy) immediately before carrageenan injection and 3 hours afterwards. The edema reduction in treated animals was expressed as percentage inhibition of the edema observed in vehicle-treated animals, taken as 100 . The results are presented as means \pm SEM. Statistical analysis was performed with ANOVA, followed by the Dunnett test.

\section{Gastrotoxicity.}

Male Wistar rats, weighing 180-200 g (Harlan, S. Pietro al Natisone, Italy) were individually housed in hanging stainless-steel cages with grid floors, at constant room temperature $\left(25 \pm 1{ }^{\circ} \mathrm{C}\right)$ and humidity $(60 \pm 5 \%$ ), with an artificial 12:12 h light/dark cycle. They were deprived of food but not of water $24 \mathrm{~h}$ before the experiments. By the intragastric route, groups of rats $(n=6)$ were given ASA 120 mgkg-1 or equimolar doses of the two selected NO-donor ASA pro-drugs, 38 and 49 (1\% CMC as vehicle). Rats were killed $3 \mathrm{~h}$ after administration of the compound. Immediately after death, the stomach was removed, opened along the lesser curvature and examined, to assess mucosal lesions. The stomach was laid on a flat surface under a stereomicroscope. The glandular mucosa was examined and each individual hemorrhagic lesion was measured along its greatest length $(<1 \mathrm{~mm}$ : rating $=1 ; 1-2 \mathrm{~mm}$ : rating $=2 ;>2 \mathrm{~mm}$ : rating according to their greatest length). The lengths of the lesions were summed to give an overall total, designated as the lesion index, for each stomach. The results are presented as means \pm SEM. Statistical analysis was performed with ANOVA, followed by the Newman-Keuls test.

\section{Acknowledgements}

This work was supported by a grant from the Italian Ministry for University and Research (MIUR), Studi e Ricerche Finalizzate 40\% Roma (PRIN2009, 2009K4NFZ4_002).

Keywords: anti-inflammatory agents · acetylsalicylic acid $\cdot$ nitric oxide $\cdot$ prodrugs $\cdot$ water solubility. 


\section{References}

1) Bandarage, U. K., Janero, D.R. . Nitric Oxide Releasing Non Steroidal Anti-inflammatory Drugs: Novel Gastrointestinal-sparing Drugs. Mini Rev. Med. Chem. 2001, 1, 57-70.

2) Turnbull, C. M.; Rossi, A. G.; Megson, I. L. Therapeutic effects of nitric oxide-aspirin hybrid drugs. Expert Opinion on Therapeutic Targets 2006, 10, 911-922.

3) Wolfe, M. M.; Lichtenstein, D. R.; Singh, G. Gastrointestinal toxicity of nonsteroidal antiinflammatory drugs. N. Engl. J. Med. 1999, 340, 1888-1899.

4) Lanas, A. Role of nitric oxide in the gastrointestinal tract. Arthritis Research \& Therapy 2008, 10 , S4.

5) Lim, Y. J.; Lee, J. S.; Ku, Y. S.; Hahm, K. B. Rescue strategies against non-steroidal antiinflammatory drug-induced gastroduodenal damage. J. Gastroenterol. Hepatol. 2009, 24, 1169-1178.

6) Gao, J. J.; Kashfi, K.; Rigas, B. In vitro metabolism of nitric oxide-donating aspirin: The effect of positional isomerism. J. Pharmacol. Exp. Ther. 2005, 312, 989-997.

7) Cena, C.; Lolli, M. L.; Lazzarato, L.; Guaita, E.; Morini, G.; Coruzzi, G.; McElroy, S. P.; Megson, I. L.; Fruttero, R.; Gasco, A. Antiinflammatory, gastrosparing, and antiplatelet properties of new NO-donor esters of aspirin. J. Med. Chem. 2003, 46, 747-754.

8) Velazquez, C. A.; Chen, Q.-H.; Citro, M. L.; Keefer, L. K.; Knaus, E. E. Second-generation aspirin and indomethacin prodrugs possessing an $\mathrm{O}(2)$-(Acetoxymethyl)-1-(2carboxypyrrolidin-1-yl)diazenium-1,2-diolate nitric oxide donor moiety: Design, synthesis, biological evaluation, and nitric oxide release studies. J. Med. Chem. 2008, 51, 1954-1961.

9) Nielsen, N. M.; Bundgaard, H. Evaluation of Glycolamide Esters and Various Other Esters of Aspirin as True Aspirin Prodrugs. J. Med. Chem. 1989, 32, 727-734.

10) Lazzarato, L.; Donnola, M.; Rolando, B.; Chegaev, K.; Marini, E.; Cena, C.; Di Stilo, A.; Fruttero, R.; Biondi, S.; Ongini, E.; Gasco, A. (Nitrooxyacyloxy)methyl Esters of Aspirin as Novel Nitric Oxide Releasing Aspirins. J. Med. Chem. 2009, 52, 5058-5068.

11) Lazzarato, L.; Chegaev, K.; Marini, E.; Rolando, B.; Borretto, E.; Guglielmo, S.; Joseph, S.; Di Stilo, A.; Fruttero, R.; Gasco, A. New Nitric Oxide or Hydrogen Sulfide Releasing Aspirins. J. Med. Chem. 54, 5478-5484.

12) Buchwald, P., Structure-metabolism relationships: Steric effects and the enzymatic hydrolysis of carboxylic esters. Mini-Rev. Med. Chem. 2001, I (1), 101-111.

13) Fechtig, B. 7-Beta-acylamido-3-cephem-4-carboxylic-acid esters, process for their preparation, pharmaceutical compositions and their application. European patent EP0136266, September 17, 1984. 
14) E. E. Weinert, R. Dondi, S. Colloredo-Melz, K. N. Frankenfield, C. H. Mitchell, M. Freccero, S. E. Rokita "Substituents on quinone methides strongly modulate formation and stability of their nucleophilic adducts" J. Am. Chem. Soc., 2006, 128, 11940-11947. 
Chart 1. General structure of NO-donor ASA prodrugs.

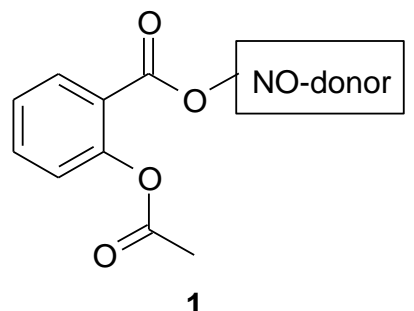

1
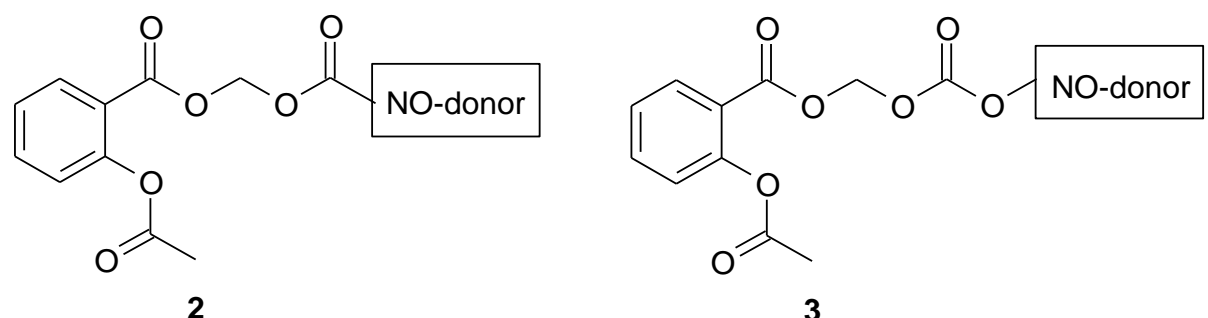
Chart 2. General structure of water soluble ASA prodrugs.

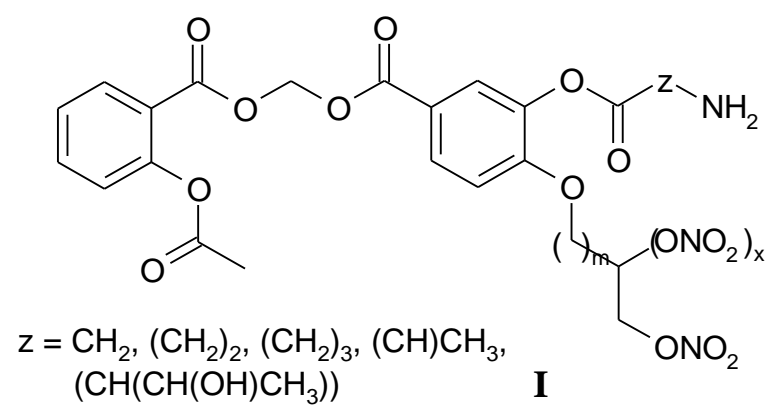<smiles>CC(=O)Oc1ccccc1C(=O)OCOC(=O)c1ccc(OCCCO[Na])c(CN2CCOCC2)c1</smiles>

$\mathrm{m}=1,2$

$\mathrm{x}=0,1$ 
Scheme 1.

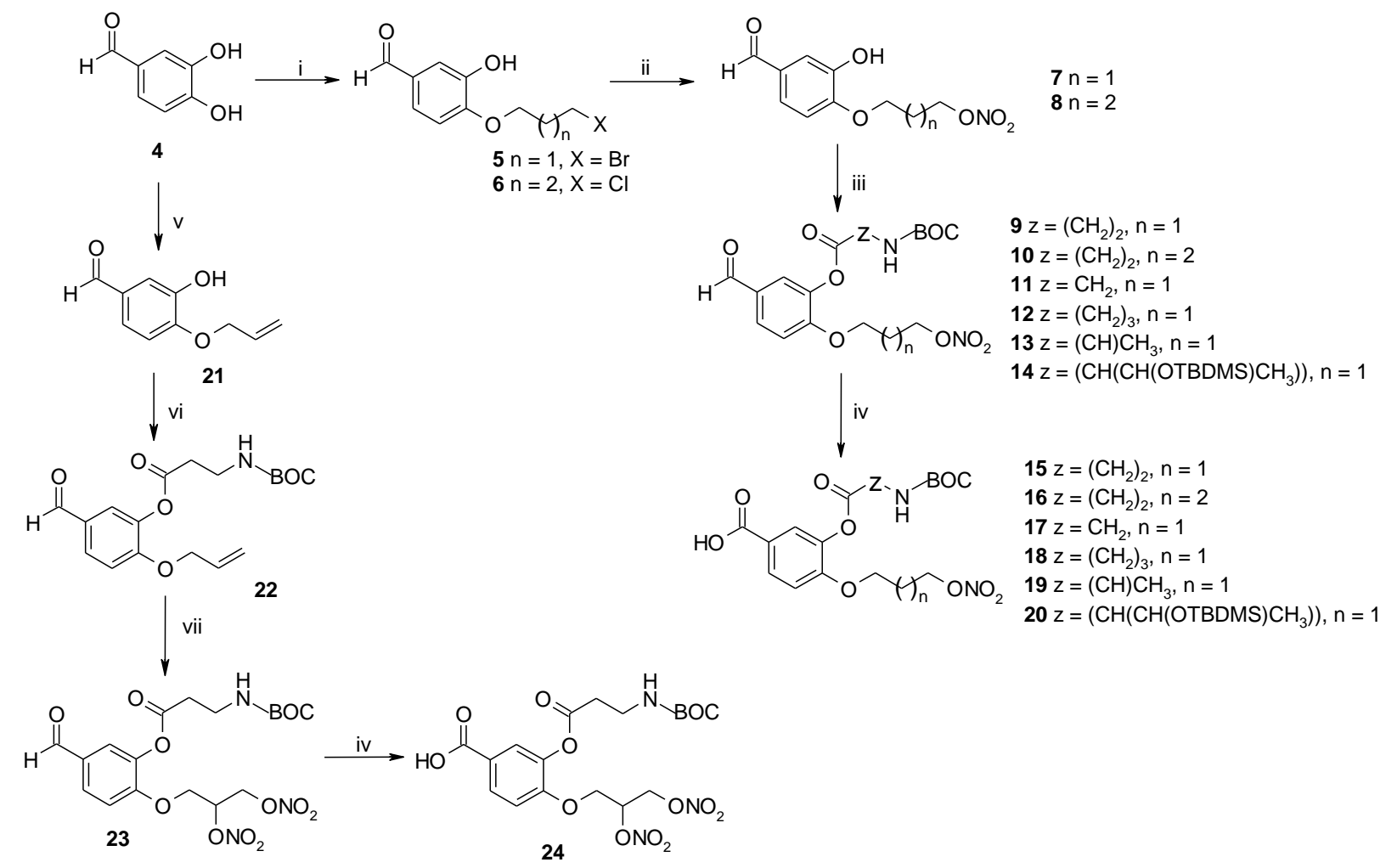

i) $\mathrm{Br}\left(\mathrm{CH}_{2}\right)_{3} \mathrm{Br}$ or $\mathrm{Br}\left(\mathrm{CH}_{2}\right)_{4} \mathrm{Cl}, \mathrm{KHCO}_{3}, \mathrm{CH}_{3} \mathrm{CN}, 70{ }^{\circ} \mathrm{C}$; ii) $\mathrm{AgNO}_{3}, \mathrm{CH}_{3} \mathrm{CN}, 70{ }^{\circ} \mathrm{C}$; iii) $\mathrm{EDC}-\mathrm{HCl}$, DMAP, N-BOCaminoacid, $\mathrm{CH}_{2} \mathrm{Cl}_{2}$; iv) $\mathrm{KMnO}_{4}$, acetone; v) $\mathrm{BrCH}_{2} \mathrm{CH}=\mathrm{CH}_{2}, \mathrm{KHCO}_{3}, \mathrm{CH}_{3} \mathrm{CN}, 70$ ${ }^{\circ} \mathrm{C}$; vi) EDC-HCl, DMAP, $\mathrm{HOOC}\left(\mathrm{CH}_{2}\right)_{2} \mathrm{NHBOC}, \mathrm{CH}_{2} \mathrm{Cl}_{2}$; vii) $\mathrm{AgNO}_{3}, \mathrm{I}_{2}, \mathrm{CH}_{3} \mathrm{CN}, 70{ }^{\circ} \mathrm{C}$ 
Scheme 2.<smiles>COC(=O)c1ccc(O)c(O)c1</smiles>

25<smiles>COC(=O)c1ccc(OCCCBr)c(O)c1</smiles>

26<smiles>COC(=O)c1ccc(OCCCO[N+](=O)[O-])c(O)c1</smiles>

27<smiles>O=C(O)c1ccc(OCCCO[N+](=O)[O-])c(O)c1</smiles>

28

i) $\mathrm{Br}\left(\mathrm{CH}_{2}\right)_{3} \mathrm{Br}, \mathrm{KHCO}_{3}, \mathrm{CH}_{3} \mathrm{CN}, 70{ }^{\circ} \mathrm{C}$; ii) $\mathrm{AgNO}_{3}, \mathrm{CH}_{3} \mathrm{CN}, 70{ }^{\circ} \mathrm{C}$; iii) $\mathrm{NaOH}, \mathrm{THF} / \mathrm{H}_{2} \mathrm{O}, 40{ }^{\circ} \mathrm{C}$. 
Scheme 3.

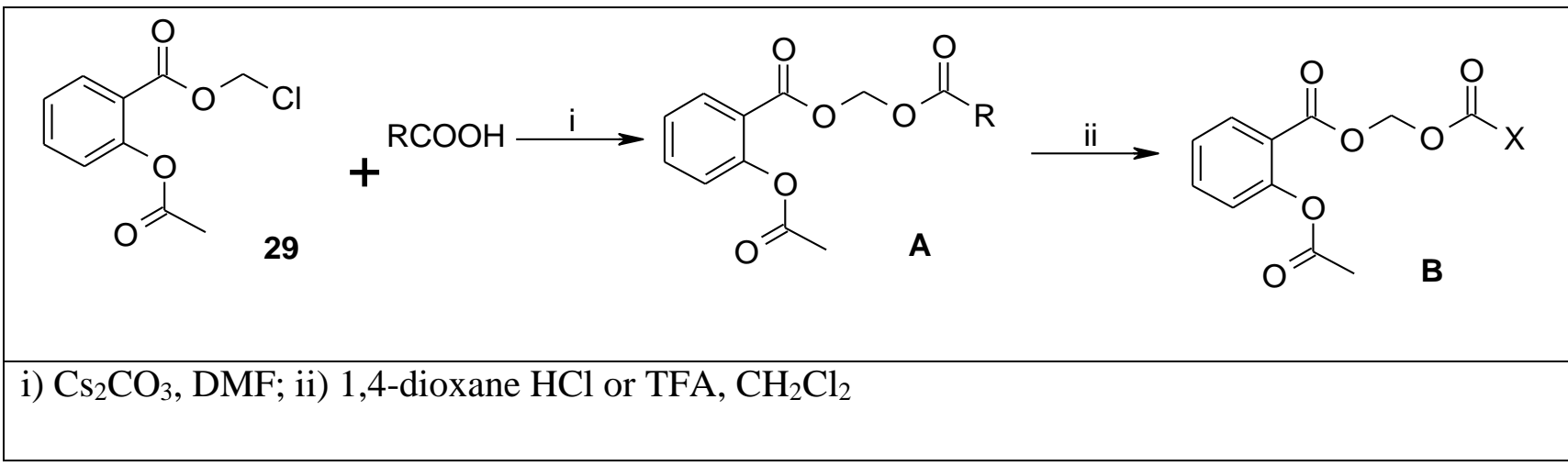

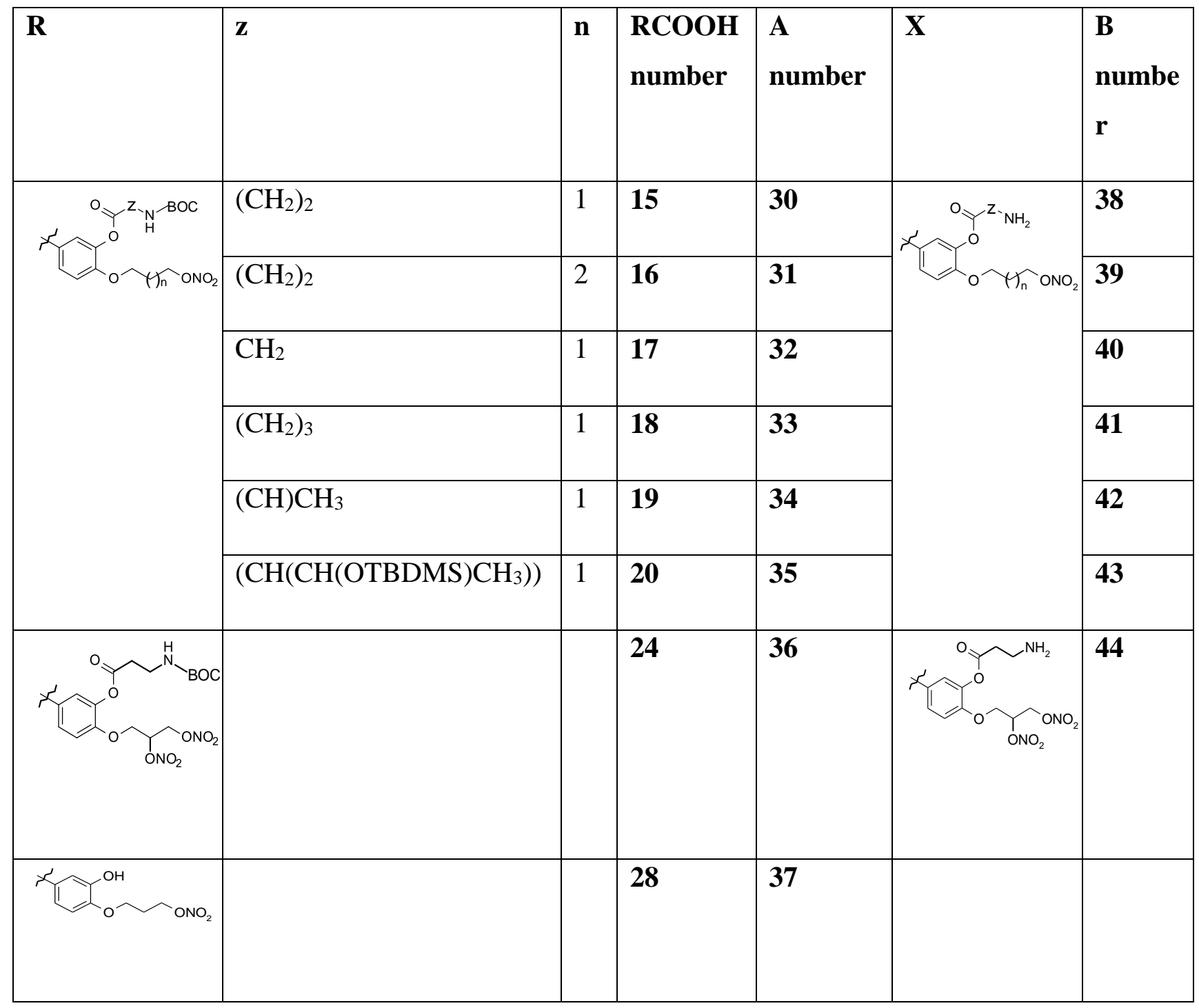


Scheme 4.<smiles>COC(=O)c1ccc(O)c(CN2CCOCC2)c1</smiles>

45
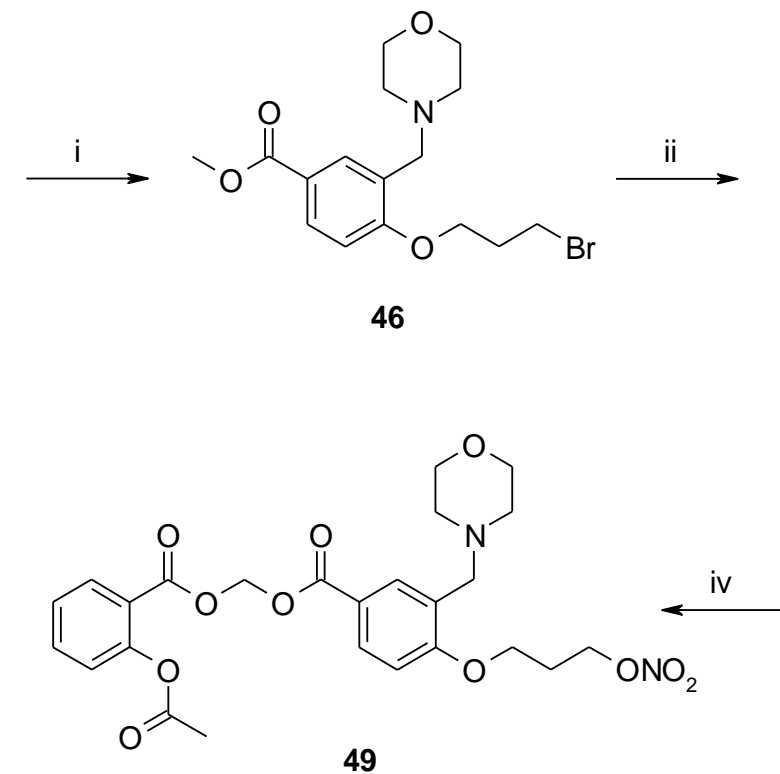<smiles>COC(=O)c1ccc(OCCCBr)c(CN2CCOCC2)c1</smiles><smiles>C1=CC2CCCC2C1</smiles><smiles>CC#C[V]</smiles>
48

$\mathrm{Br}\left(\mathrm{CH}_{2}\right)_{3} \mathrm{Br}, \mathrm{CH}_{3} \mathrm{CN}, \mathrm{K}_{2} \mathrm{CO}_{3}, 70{ }^{\circ} \mathrm{C}$; ii) $\mathrm{AgNO}_{3}, \mathrm{CH}_{3} \mathrm{CN}, 70{ }^{\circ} \mathrm{C}$; iii) $1 \mathrm{~N} \mathrm{NaOH}$, $\mathrm{MeOH}$, r.t.; iv) 29, $\mathrm{Cs}_{2} \mathrm{CO}_{3}$, DMF. 
Scheme 5. Possible hydrolytic routes of prodrugs bearing aminoacyloxy (A) and morpholino (B) solubilizing substructure.

A

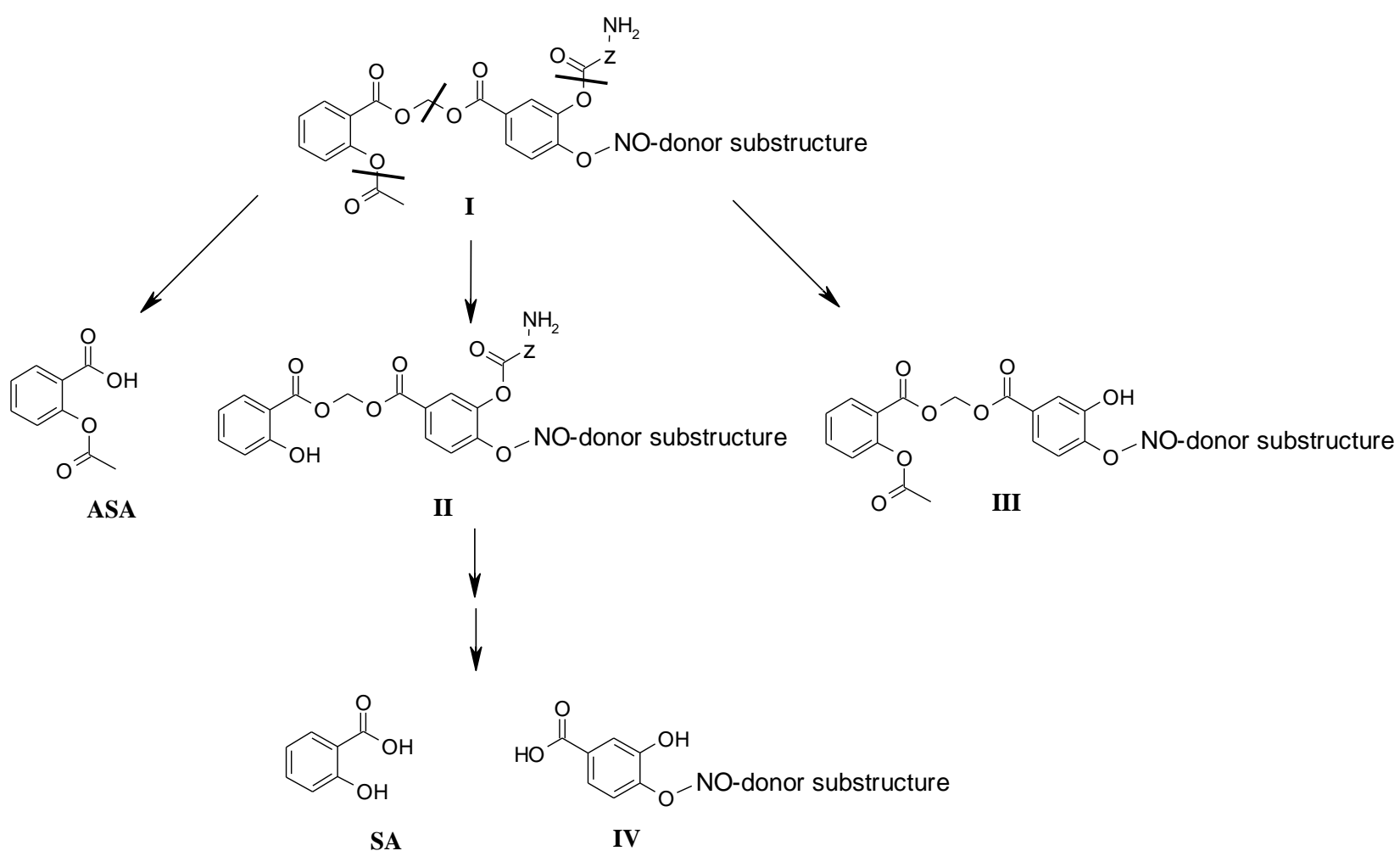

B

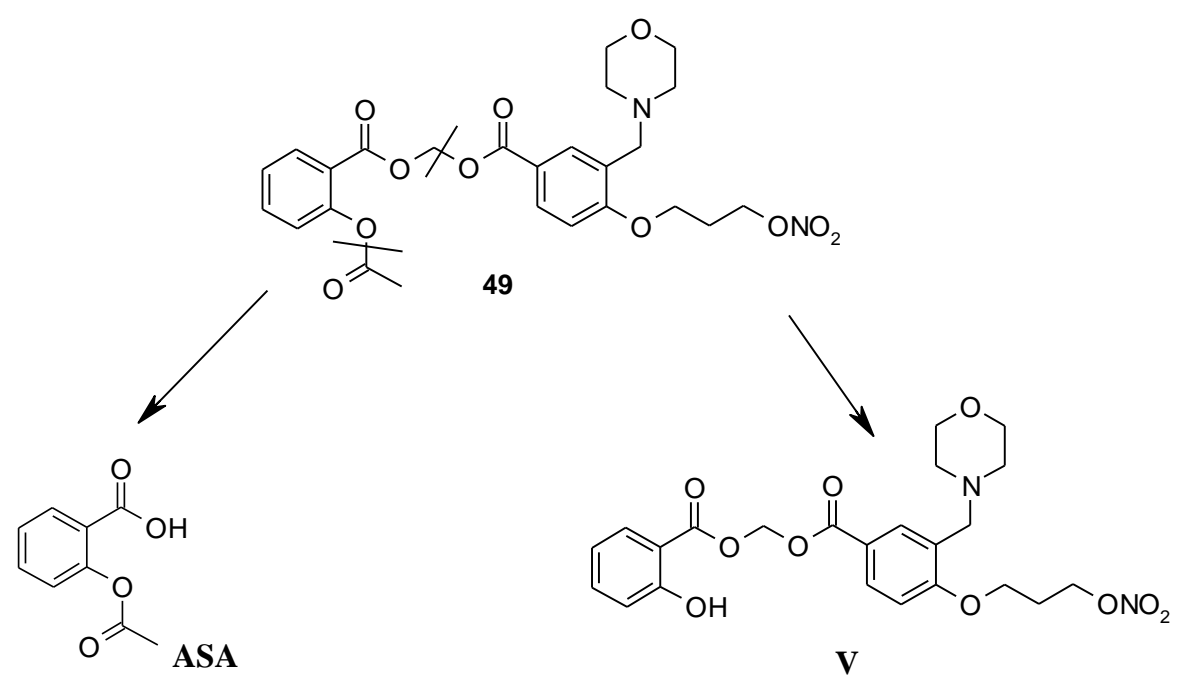<smiles>O=C(O)c1ccccc1O</smiles><smiles>CC1CC12CCCC2</smiles>

SA

48 



\begin{tabular}{|c|c|c|c|c|c|c|c|}
\hline \multirow[b]{2}{*}{ compd } & \multirow{2}{*}{$\begin{array}{l}\text { M.P. } \\
\left({ }^{\circ} \mathrm{C}\right)\end{array}$} & \multirow{2}{*}{$\begin{array}{l}\text { Solubility } \\
\left(\mathrm{g} \mathrm{L}^{-1}\right)\end{array}$} & \multicolumn{2}{|c|}{$\begin{array}{l}\text { Stability in buffered } \\
\text { solutions }\end{array}$} & \multicolumn{2}{|c|}{$\begin{array}{l}\text { Stability and ASA released in } \\
\text { human serum }\end{array}$} & \multirow{2}{*}{$\begin{array}{l}\begin{array}{l}\text { Platelet } \\
\text { aggregation }\end{array} \\
\mathrm{IC}_{50}(\mu \mathrm{M}) \\
(\mathrm{CL} 95 \%)\end{array}$} \\
\hline & & & $\begin{array}{l}\mathrm{pH} 1 \\
\% \\
\text { unchanged } \\
\text { after } 3 \mathrm{~h}^{[\mathrm{b}]}\end{array}$ & $\begin{array}{l}\text { pH } 7.4 \\
t_{1 / 2}(\min )^{[c]}\end{array}$ & $t_{1 / 2}(\min )$ & $\begin{array}{l}\% \text { max of ASA } \\
\text { released }^{[f]} \\
\text { AUC }_{0-10 \min }\end{array}$ & \\
\hline $\mathrm{ASA}^{10}$ & - & & 90 & 90 & 63 & $\begin{array}{l}- \\
954\end{array}$ & $\begin{array}{l}54 \\
(49-60)\end{array}$ \\
\hline 38 & $94.5-95.5$ & 56 & 88 & 57 & $<1$ & $\begin{array}{l}55 \% \\
528.0\end{array}$ & $\begin{array}{l}23 \\
(20-28)\end{array}$ \\
\hline 39 & oil & 52 & 98 & 86 & $<1$ & $\begin{array}{l}50 \% \\
336.2\end{array}$ & $\begin{array}{l}47 \\
(41-54)\end{array}$ \\
\hline 40 & $60.5-62.5$ & 110 & 70 & 12 & $<1$ & $\begin{array}{l}57 \% \\
381.6\end{array}$ & $\begin{array}{l}40 \\
(34-48)\end{array}$ \\
\hline 41 & oil & 32 & 90 & 10 & $<1$ & $\begin{array}{l}50 \% \\
217.3\end{array}$ & $\begin{array}{l}139 \\
(126-154)\end{array}$ \\
\hline 42 & $65.5-69.0$ & 86 & 70 & 10 & $<1$ & $\begin{array}{l}55 \% \\
232.0\end{array}$ & $\begin{array}{l}107 \\
(97-119)\end{array}$ \\
\hline 43 & $87.5-88.5$ & 70 & 90 & 15 & $<1$ & $\begin{array}{l}56 \% \\
397.5\end{array}$ & $\begin{array}{l}35 \\
(31-40)\end{array}$ \\
\hline 44 & foam & 63 & 80 & 20 & $<1$ & $\begin{array}{l}50 \% \\
251.8\end{array}$ & $\begin{array}{l}93 \\
(71-123)\end{array}$ \\
\hline 49 & $\begin{array}{l}135-139 \\
\text { dec. }\end{array}$ & 2.0 & 98 & $98^{[\mathrm{d}]}$ & $2.2^{[\mathrm{e}]}$ & $\begin{array}{l}30 \% \\
189.2\end{array}$ & $\begin{array}{l}77 \\
(70-84)\end{array}$ \\
\hline 28 & - & - & - & - & - & - & $0.87 \pm 0.44^{[\mathrm{g}]}$ \\
\hline 48 & - & - & - & - & - & - & $7.4 \pm 5.0^{[\mathrm{g}]}$ \\
\hline
\end{tabular}


Figure 1. A. Concentration over time of the prodrug 38 and its metabolites in human serum during 3 hours' incubation. B. Detail of concentration of compounds during the first 10 min of incubation. Values are means \pm SEM $($ SEM $<1 ; n=3)$.

A

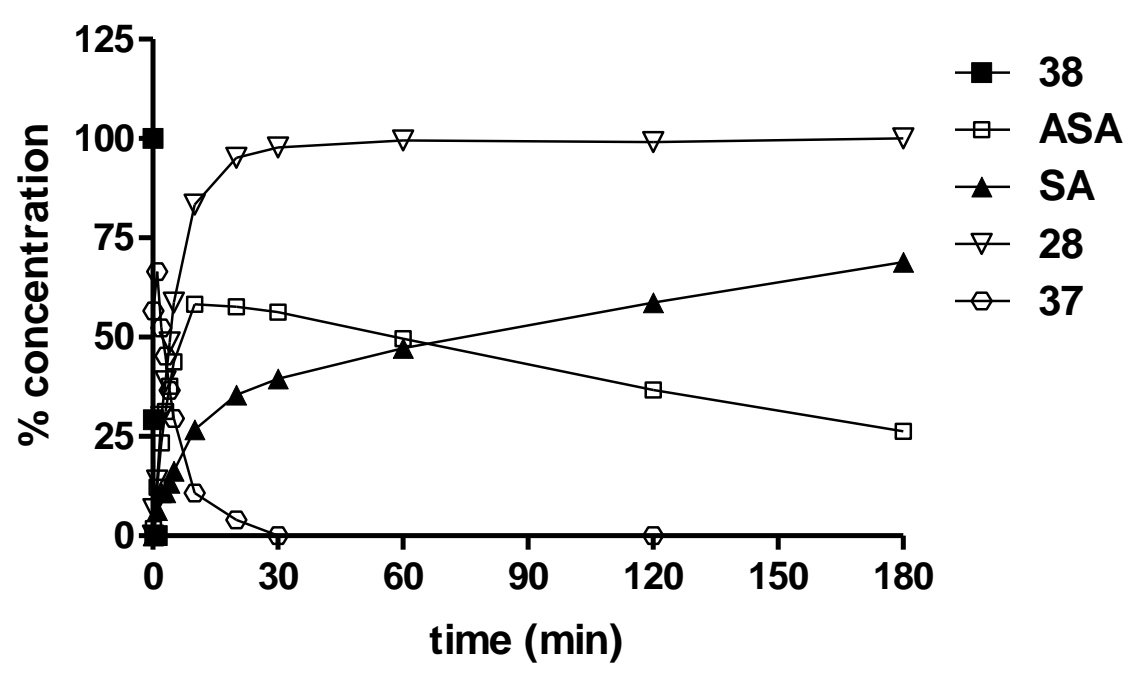

B

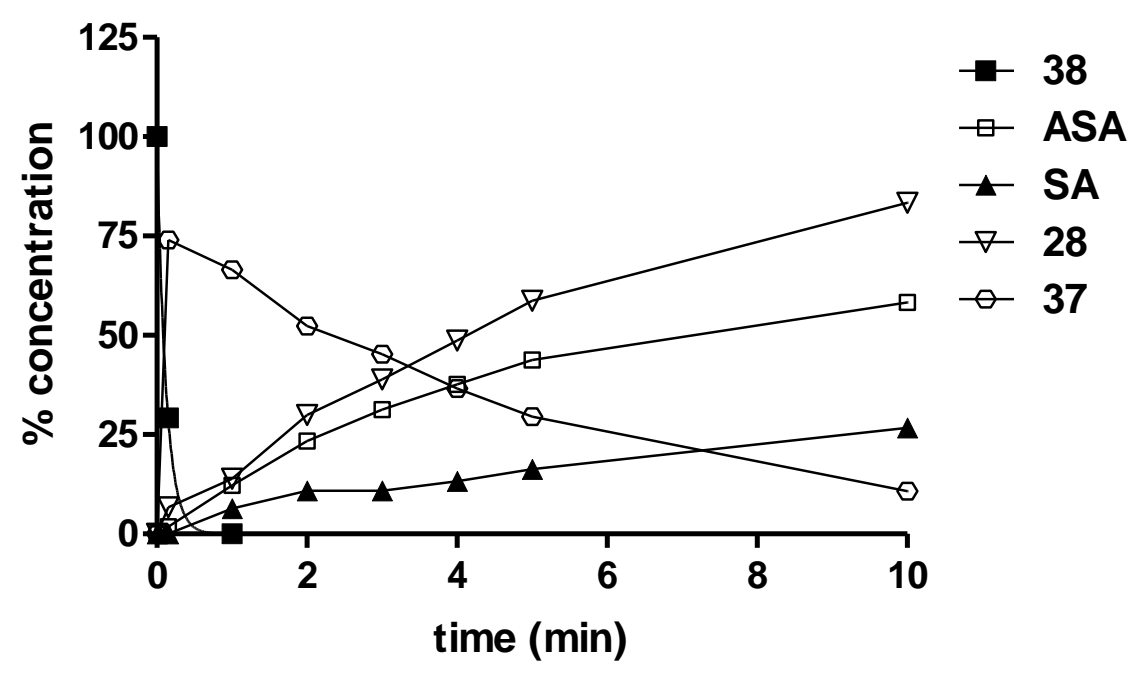


Figure 2. A. Concentration over time of the prodrug 49 and its metabolites in human serum during 3 hours' incubation. B. Detail of concentration of compounds over the first $10 \mathrm{~min}$ of incubation. Values are means \pm SEM $($ SEM $<1 ; n=3)$.

A

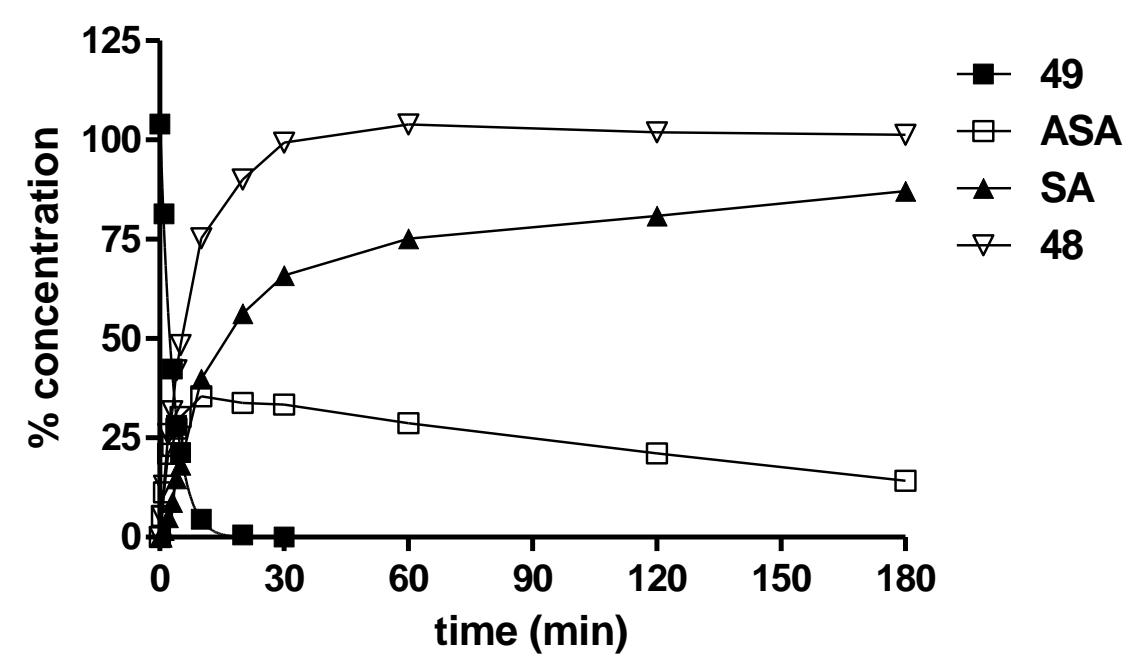

B

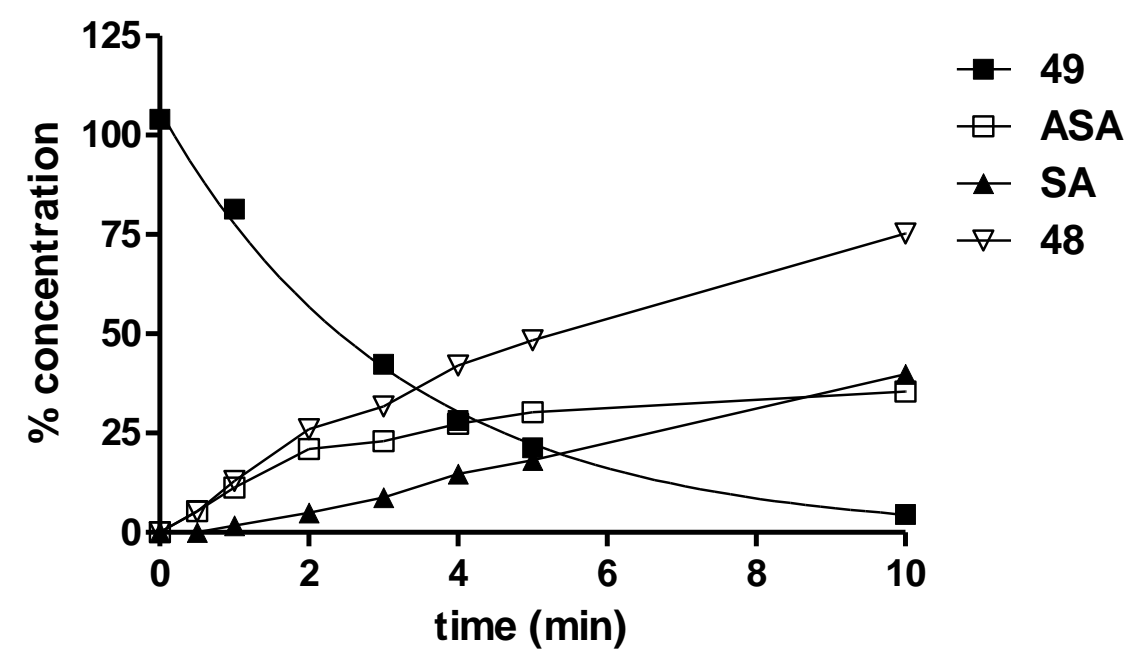


Figure 3. Correlation between ASA released during the first 10 minutes of incubation in human serum (area under curve, $\left.\mathrm{AUC}_{0-10}\right)$ and antiaggregatory activity $\left(\mathrm{IC}_{50}\right)$.

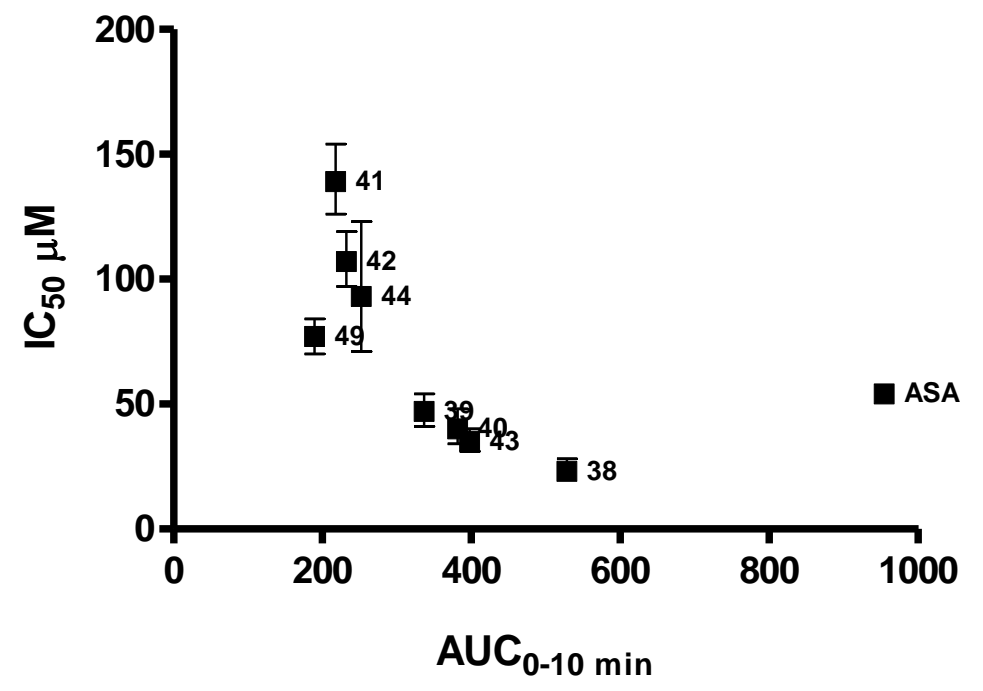


Figure 4. A. Anti-inflammatory effects of aspirin and NO-donor ASA prodrugs, 38 and 49, on carrageenan-induced paw edema in conscious rats. The aspirin-like compounds were administered by the intragastric route at doses equimolar to aspirin, $120 \mathrm{mg} / \mathrm{kg}$, at the same time as carrageenan, and their effects were evaluated $3 \mathrm{~h}$ later. Results are expressed as the percentage inhibition of edema versus the vehicle-treated group, taken arbitrarily as 100 . $(\star \star) p<0.01$ versus vehicle (ANOVA, followed by the Dunnett test). Values are means $\pm \operatorname{SEM}(n=6$ rats per group). B. Gastric ulcerogenic effects of aspirin, and NO-donor ASA prodrugs, 38 and 49, in conscious rats. The aspirin-like compounds were administered by the intragastric route at doses equimolar to aspirin, $120 \mathrm{mg} / \mathrm{kg}$, and the stomach examined $3 \mathrm{~h}$ later. Gastric lesions were measured along the greatest length, and the cumulative length in millimeters was designated as the "lesion index" for each stomach. All the compounds tested produced significantly less gastric damage than aspirin $(\star \star) p$ $<0.01$; (ANOVA and the Newman-Keuls test). Values are means \pm SEM ( $n=6$ rats per group).
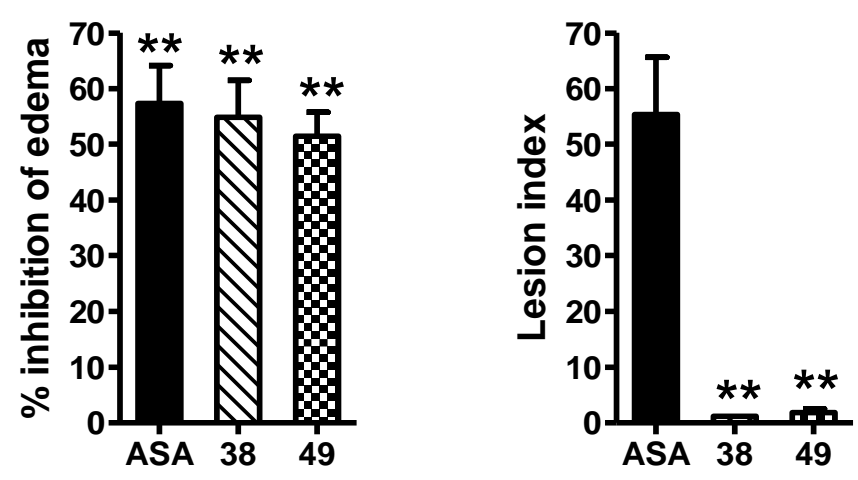